\title{
Synthesis and Characterization of Aluminum Carbide-Derived Carbon with Residual Aluminum-Based Nanoparticles
}

Colton M. Moran ${ }^{a}$, Robert M. Marti ${ }^{b}$, Sophia E. Hayes ${ }^{b}$ Krista S. Walton ${ }^{a^{*}}$

${ }^{a}$ C. M. Moran, Prof. K. S. Walton

School of Chemical and Biomolecular Engineering

Georgia Institute of Technology

311 Ferst Drive NW

Atlanta, Georgia 30332 USA

E-mail: krista.walton@ chbe.gatech.edu

${ }^{\mathrm{b}}$ R. M. Marti, Prof. S. E. Hayes

Department of Chemistry

Washington University in St. Louis

St. Louis, MO 63130 USA

E-mail: hayes@wustl.edu

An in-depth study on the etching process for producing carbide-derived carbons from $\mathrm{Al}_{4} \mathrm{C}_{3}$ has been performed. These materials were investigated at a range of etching temperatures from 300 to $900{ }^{\circ} \mathrm{C}$ and a range of times from 15 minutes to 6 hours. By altering the etching time and temperature, the surface area, residual aluminum content, and pore size distribution can be turned. A maximum surface area of $1126 \mathrm{~m}^{2} \mathrm{~g}^{-1}$ was observed for materials etched at $500{ }^{\circ} \mathrm{C}$ for 1h. The pore size has shown to be tunable from $\leq 0.7$ to $8 \mathrm{~nm}$. Interestingly, aluminum-based nanoparticles were observed via TEM and SEM for partially etched samples, with evidence of tunable metal species on the surface of the $\mathrm{Al}_{4} \mathrm{C}_{3}-\mathrm{CDC}$ samples at different etching temperatures between 300 and $700^{\circ} \mathrm{C}$. Characterization of the aluminum species present over this temperature range took place using solid-state ${ }^{27} \mathrm{Al}$ NMR. The formation of crystalline $\alpha-\mathrm{Al}_{2} \mathrm{O}_{3}$ was observed at etching temperatures of $700{ }^{\circ} \mathrm{C}$. The results of this work provide detailed synthesis strategies for controlling not only the porosity and surface area of a carbide-derived carbon, but also the extent and type of residual metal nanoparticles embedded in the final structure.

*Corresponding author. Tel: (404) 894-5254. E-mail: krista.walton@ chbe.gatech.edu (Krista Walton) 


\section{Introduction}

The synthesis and characterization of porous solids impact a variety of applications ranging from water purification to carbon dioxide capture.[1-3] Carbons lack the "designable" aspect of metal-organic frameworks, for example, but exhibit very high surface areas and pore volumes and continue to be the leader in the commercial use due to low cost and good adsorption capabilities covering a wide range of adsorbate molecules.[4] Activated carbons from traditional precursors such as wood and fruit pits or shells are known to exhibit wide pore size distributions with curved porous networks that lead to a bottle-neck effect which restricts molecule access and slows molecular diffusion.[5] In recent years, a class of tailorable porous-carbon materials, carbide-derived carbons (CDCs), have emerged as promising materials for hydrogen and methane storage, electrochemical energy storage, protein adsorption, and pollution removal from both water and air.[6-11] CDCs are thermally and chemically resistant, making them applicable in a wide range of environmental conditions. These highly porous-carbon materials demonstrate a tunable, narrow pore-size distribution and surface areas exceeding $2000 \mathrm{~m}^{2} \mathrm{~g}^{-1}$ for nonchemically activated species and over $3000 \mathrm{~m}^{2} \mathrm{~g}^{-1}$ for chemically activated material. $[9,12]$

A multitude of binary and ternary carbides are used as precursors to CDC production, each precursor leading to a unique porous-carbon material with distinguishable physical features and potential applications. [13] By altering the precursor, the resulting trends seen in the physical characteristics of the CDC change, from the pore size distribution to the type of ordered carbon structures observed. Along with precursor selection, the metal extraction method plays a significant role in the resulting CDC. Multiple methods may be implemented for metal removal, such as halogenation, hydrothermal treatment, and vacuum decomposition.[13] A large body of current literature focuses on utilizing chlorine gas to create metal chlorides as a means of

*Corresponding author. Tel: (404) 894-5254. E-mail: krista.walton@ chbe.gatech.edu (Krista Walton) 
halogenation treatment for metal extraction. During this process the metal heteroatom of the carbide precursor reacts with the chlorine gas forming a metal chloride that diffuses out of the developing porous-carbon structure.

Metal free porous-carbon materials have been the focus of most CDC research to date, with the exception of partially etched $\mathrm{Fe}_{3} \mathrm{C}-\mathrm{CDC}$.[14] Partial etching is the process of halting the chlorination reaction before complete extraction of the metal species. Mangarella et. al. demonstrated that partially etching $\mathrm{Fe}_{3} \mathrm{C}-\mathrm{CDC}$ produced iron chloride nanoparticles scattered throughout the $\mathrm{Fe}_{3} \mathrm{C}-\mathrm{CDC}$ matrix.[14, 15] The addition of such metal sites in porous-carbon materials is more typically accomplished by post-synthetic metal impregnation in activated carbon and pre-synthetic microemulsion in SiC-CDC.[16-18] Incorporation of metal-based active sites has improved adsorption and catalytic properties for carbonaceous support materials, but these properties are often diffusion limited due to partial pore blockage by the impregnant. The generation of metal impregnated porous-carbon materials can be achieved via different methods, with wet impregnation techniques utilized in a vast majority of current literature. These procedures, specifically wet impregnation, require time-consuming steps during preparation such as washing cycles, drying and in some cases decomposition steps for nitrate impregnated materials, all of which are ancillary to the process to generate the activated carbon and the initial impregnation step.[19-25] These methods also require additional raw materials such as the metal source and solvent for impregnation. All of these additional steps and resources exponentially increase processing cost for future scale up, limiting the economic viability of the materials. The process of partially etching carbide materials has the potential to generate a porous-carbon with active metal-based sites in the form of nanoparticles, which can be synthesized in a matter of hours rather than days. Therefore, it is advantageous to investigate metal-carbide precursors that

*Corresponding author. Tel: (404) 894-5254. E-mail: krista.walton@ chbe.gatech.edu (Krista Walton) 
can be partially etched to yield tunable pore sizes and additional adsorption sites in and on the adsorbent in the form of metal based nanoparticles, without additional processing steps or reduction of the porous-carbon properties. $\mathrm{Fe}_{3} \mathrm{C}-\mathrm{CDCs}$, which have demonstrated the presence of nanoparticles, is hypothesized to retain $\mathrm{FeCl}_{\mathrm{x}}$ nanoparticles due to the agglomeration of vaporized iron chloride in parallel with particles being trapped by carbon structures due to iron chloride's catalysis of graphitic structures.[14] These results have motivated an investigation into other carbide materials that have the capacity to create active sites from the metal present in the carbide precursor via a partial etching process.

Aluminum chloride $\left(\mathrm{AlCl}_{3}\right)$, generated during the chlorination of aluminum carbide $\left(\mathrm{Al}_{4} \mathrm{C}_{3}\right)$ provided the possibility for similar retention of nanoparticles due to the unique properties of the chloride. $\mathrm{AlCl}_{3}$ sublimes at $180^{\circ} \mathrm{C}$ allowing access to a low range of etching temperatures. The chloride exists as both a monomer and dimer at different etching conditions, effecting how the vaporized chloride diffuses through the structure.[26] The equilibrium from the larger dimer to the smaller monomer will affect how the metal chloride can diffuse out of the porous carbon structure. $\mathrm{AlCl}_{3}$ has shown the ability to polymerize in the presence of liquid water to form polyaluminum chloride (PAC) as well as go through gas phase hydrolysis in the presence of trace amounts of water vapor. It has also been demonstrated that $\mathrm{AlCl}_{3}$ reacts in the presence of oxygen, utilizing a chlorine catalyst at moderate temperatures to form $\mathrm{Al}_{2} \mathrm{O}_{3}$. [26-32] These properties motivated an investigation into the potential for partially etched $\mathrm{Al}_{4} \mathrm{C}_{3}-\mathrm{CDC}$ materials to contain nanoparticles. Studies have shown that $\mathrm{Al}_{2} \mathrm{O}_{3}$ nanoparticles display enhanced reactivity with both acid gas and volatile organic compound in terms of adsorption.[33, 34] Aluminum hydroxide particles have also demonstrated favorable adsorption properties with phosphates, as a result of the hydroxyl groups.[35] Therefore, it could be advantageous to *Corresponding author. Tel: (404) 894-5254. E-mail: krista.walton@ chbe.gatech.edu (Krista Walton) 
incorporate aluminum based nanoparticles into a porous-carbon structure in a one pot synthesis, without reducing or hindering the carbon properties for adsorption based applications. Specifically, the various polymorphs of aluminum oxide and aluminum hydroxide have shown favorable interactions with acid gases due to their amphoteric nature.[34, 36, 37] To the best of the authors' knowledge, no prior studies have examined the interactions between acid gases and aluminum oxide/aluminum hydroxide nanoparticles embedded in a carbon matrix. By combining the adsorption properties of the porous-carbon and those of aluminum-based nanoparticles, a chemically and thermally resistant adsorbent can be produced and tuned for adsorption as investigated with the weak acid gas, $\mathrm{CO}_{2}$, as part of this work. A future application of such a material would exist in any place where a resilient sorbent is necessary for the removal or adsorption of toxic and corrosive gases such as in flue gas applications. Therefore, a focused study on the synthesis of partially etched $\mathrm{Al}_{4} \mathrm{C}_{3}-\mathrm{CDCs}$ and their respective interaction with $\mathrm{CO}_{2}$ and $\mathrm{H}_{2} \mathrm{O}$ is of fundamental importance.

Fully etched $\mathrm{Al}_{4} \mathrm{C}_{3}-\mathrm{CDCs}$ have been documented in literature at a variety of etching conditions, citing a range of carbon based properties. These studies focused on electrical properties, such as capacitance, as well as observing carbon structure formation. [38-43] References to aluminum based material was briefly stated in Perkson et. Al., with a stated assumption of the material being aluminum chloride stuck in the pores, which is widely assumed in literature for residual metal in CDCs.[38] To the best of the authors' knowledge, an in-depth study on partially etched $\mathrm{Al}_{4} \mathrm{C}_{3}$-CDCs has not been conducted. Nor has a complete study on pore size distribution and surface area as a function of etching time and temperature been completed to a degree to satisfy a full understanding of the correlation between synthesis conditions and resulting CDC properties. Herein, the effect of chlorination time and temperature on $\mathrm{Al}_{4} \mathrm{C}_{3}$-CDC

*Corresponding author. Tel: (404) 894-5254. E-mail: krista.walton@ chbe.gatech.edu (Krista Walton) 
is studied to determine the effect on residual metal, material porosity, and pore size distribution. Additionally, water and $\mathrm{CO}_{2}$ adsorption isotherms were investigated for $\mathrm{Al}_{4} \mathrm{C}_{3}-\mathrm{CDC}$ materials etched at various temperatures and times to determine how the changes in physical properties of partially etched $\mathrm{Al}_{4} \mathrm{C}_{3}$-CDC materials affected adsorption capacity.

\section{Experimental Section}

\subsection{Materials}

$\mathrm{Al}_{4} \mathrm{C}_{3}-\mathrm{CDC}$ was prepared by depositing $1 \mathrm{~g}$ of $\mathrm{Al}_{4} \mathrm{C}_{3}$ (Strem Chemicals $98 \%$ purity -325 mesh) in a quartz boat which is placed in a 20 " long quartz tube with an outer diameter of 1 ". The tube was placed in a horizontal tube furnace that was operated in the range of $300-900^{\circ} \mathrm{C}$ with a ramp rate for heating and cooling set at $5{ }^{\circ} \mathrm{C} \mathrm{min}^{-1}$. During heating and cooling a stream of argon gas (Airgas 99.999\%) is flown over the bed at $150 \mathrm{~mL} \mathrm{~min}^{-1}$. Once the temperature reaches the desired etching temperature, chlorine gas (Airgas 99.5\%) was introduced via an Aalborg mass flow controller at a rate of $40 \mathrm{~mL} \mathrm{~min}{ }^{-1}$ while argon is still flowing at $150 \mathrm{~mL} \mathrm{~min}^{-1}$. The flow continues for the duration of the run. After the argon and chlorine have passed over the bed it goes through a $\mathrm{NaOH}$ scrubber solution to neutralize any acidic gases. Once the etching experiment was completed, chlorine flow was discontinued and the system is cooled under argon at $150 \mathrm{~mL} \mathrm{~min}^{-1}$. Note, for the sake of clarity the samples are labeled as follows $\mathrm{Al}_{4} \mathrm{C}_{3}$-CDC-TCT. Where $\mathrm{Al}_{4} \mathrm{C}_{3}$ denotes the species of carbide, $\mathrm{CDC}$ refers to the general material of carbidederived carbon, $\mathrm{T}$ is the temperature in degrees Centigrade at which etching occurred at, $\mathrm{CT}$ is the chlorination time in hours (e.g. $\mathrm{Al}_{4} \mathrm{C}_{3}$-CDC-300-1h).

\subsection{Methods}

\subsubsection{Power X-ray Diffraction}

Power X-ray Diffraction (PXRD) patterns were collected using an X'Pert X-ray PANalytical diffractometer with a $\mathrm{Cu} \mathrm{K \alpha}$ X-ray source $(\lambda=1.5418 \AA$ ). PXRD diffractograms *Corresponding author. Tel: (404) 894-5254. E-mail: krista.walton@ chbe.gatech.edu (Krista Walton) 
were collected from a range of $5-90^{\circ}$ with a step size of $0.02^{\circ}$. All experiments were carried out at room temperature.

\subsubsection{Nitrogen Sorption Measurements}

Nitrogen sorption measurements at $77 \mathrm{~K}$ were obtained using a Quantachrome Quadrasorb SI volumetric analyzer. Isotherms were collected at $77 \mathrm{~K}$ using a sample of 15-45 mg. Prior to each isotherm, the sample was outgassed for approximately 18 hours at $150^{\circ} \mathrm{C}$ and under vacuum (approximately 20 mTorr). Specific surface areas were calculated using the BET model in the relative pressure range $\left(\mathrm{P} / \mathrm{P}_{0}\right)$ 0.005-0.03. Pore size distributions were collected for all samples using the Quenched Solid Density Functional Theory (QSDFT) model built into version 5.11 QuadraWin ${ }^{\mathrm{TM}}$ software. The QSDFT parameters were selected depending on the characteristics of the isotherm. For microporous, type I isotherms, a slit-pore model, nitrogen adsorbate, and carbon adsorbent were assumed. Whereas, for type IV isotherms that exhibit characteristic cavitation effects, an adsorption branch slit-pore/cylindrical pore model was used with an assumed nitrogen adsorbate and carbon adsorbent.

\subsubsection{Thermogravimetric Analysis (TGA)}

Thermogravimetric analysis for all samples was carried out on a NETZSCH STA 449 F1 Jupiter instrument. Measurements used 10-40 mg of material, ramped from $25-1400{ }^{\circ} \mathrm{C}$ at a ramp rate of $10{ }^{\circ} \mathrm{C} \mathrm{min}^{-1}$ and a flow rate of $20 \mathrm{~mL} \mathrm{~min}^{-1}$ of air (Airgas 99.999\%). The residual metal content was calculated by assuming total combustion of carbon, upon complete combustion, the final mass was assumed to be $\mathrm{Al}_{2} \mathrm{O}_{3}$.

*Corresponding author. Tel: (404) 894-5254. E-mail: krista.walton@ chbe.gatech.edu (Krista Walton) 


\subsubsection{Magic-Angle Spinning Nuclear Magnetic Resonance (MAS NMR)}

No pretreatment of the sample was done before taking NMR measurements. ${ }^{27} \mathrm{Al}$ MAS NMR was carried out for all samples at a magnetic field strength of $13.9 \mathrm{~T}$. A rotor synchronized (40 $\mu$ s rotor period, corresponding to a spinning speed of $25 \mathrm{kHz}$ ) Hahn echo pulse sequence with a central transition-selective pulse was employed (CT pulse width $=1.3 \mu$ s). All spectra were referenced to a solution of $1 \mathrm{M} \mathrm{Al}\left(\mathrm{NO}_{3}\right)_{3}$ at $0.0 \mathrm{ppm}$. The ${ }^{27} \mathrm{Al}$ spectra were recorded on a Redstone NMR spectrometer (TecMag) at a Larmor frequency of 153.7 MHz. For acquisition of the ${ }^{27} \mathrm{Al}$ spectra, a Bruker HX MAS probe with a $2.5 \mathrm{~mm}$ rotor was used. Additional measurements were recorded for select samples using a pulse-acquire experiment at a magnetic field strength of $20.0 \mathrm{~T}$, spinning at $33.3 \mathrm{kHz}$, and a flip angle of $\pi / 18[1]$ (corresponding to a pulse width of $0.36 \mu$ s) to ensure quantitative[2] 1D spectra were recorded.

\subsubsection{Scanning electron microscopy (SEM)}

Scanning electron microscopy (SEM) images were obtained using a LEO 1530 Thermally-Assisted Field Emission (TFE) Scanning Electron Microscope (SEM). All samples were deposited onto carbon tape. Images were scanned at an accelerating voltage range of 6-10 $\mathrm{kV}$.

\subsubsection{Transmission electron microscopy (TEM)}

TEM and HRTEM images were obtained using a FEI Tecnai F30 at an operating voltage of $300 \mathrm{kV}$ with a $1.7 \AA$ point resolution. Samples were prepared by suspending approximately 1 $\mathrm{mg}$ in methanol and deposited onto a lacy carbon copper grid.

*Corresponding author. Tel: (404) 894-5254. E-mail: krista.walton@ chbe.gatech.edu (Krista Walton) 


\subsubsection{Water Vapor Adsorption Isotherms}

Water vapor adsorption experiments were performed on a volumetric Micromeritics 3Flex device for pressures up to $1 \mathrm{bar}$ at $25^{\circ} \mathrm{C}$. Prior to the measurement, $10-30 \mathrm{mg}$ of material were activated in situ at $150^{\circ} \mathrm{C}$ for 5 hours under dynamic vacuum

\subsection{8. $\mathrm{CO}_{2}$ Adsorption Measurements}

$\mathrm{CO}_{2}$ isotherms at $25{ }^{\circ} \mathrm{C}$, in the pressure range of $0-20$ bar, were obtained using the Hiden Isochema IGA-001 microbalance. Prior to the measurement, 10-30 mg of material was heated insitu at $150{ }^{\circ} \mathrm{C}$ for 18 hours under vacuum.

\subsubsection{X-ray Photoelectric Spectroscopy (XPS) analysis}

XPS measurements were taken on a Thermo K-alpha, monochromated Al Ka source with

a double-focusing hemispherical analyzer. High resolution spectra were taken of O1s, Al2p, $\mathrm{Cl} 2 \mathrm{p}$ at a $0.1 \mathrm{eV}$ step size, $50 \mathrm{~ms}$ dwell time, $50 \mathrm{eV}$ pass energy, and a $400 \mu \mathrm{m}$ spot size.

\section{Results and Discussion}

3.1. Etching temperature and time effects on residual metal in $\mathrm{Al}_{4} \mathrm{C}_{3}-\mathrm{CDC}$

$\mathrm{Al}_{4} \mathrm{C}_{3}$ reacts with chlorine gas to form aluminum chloride in the following manner:[44]

$$
\begin{aligned}
& \mathrm{Al}_{4} \mathrm{C}_{3}+6 \mathrm{Cl}_{2} \rightarrow 4 \mathrm{AlCl}_{3}+3 \mathrm{C} \\
& \mathrm{Al}_{4} \mathrm{C}_{3}+6 \mathrm{Cl}_{2} \rightarrow 2 \mathrm{Al}_{2} \mathrm{Cl}_{6}+3 \mathrm{C}
\end{aligned}
$$

Note that, depending on the temperature, the monomer and dimer of aluminum chloride will be present in different ratios in the vapor phase.[26] Near the sublimation point of aluminum *Corresponding author. Tel: (404) 894-5254. E-mail: krista.walton@ chbe.gatech.edu (Krista Walton) 
chloride, $180{ }^{\circ} \mathrm{C}$, the vaporous species is almost completely dimeric. At elevated temperatures, the equilibrium of aluminum chloride shifts to the monomeric species.[26] For the highest etching temperature reached in these experiments, $900^{\circ} \mathrm{C}$, it has been shown that the majority of sublimed aluminum chloride species exist in the monomer phase.[26, 45] The carbide was reacted at temperatures ranging from $300-900^{\circ} \mathrm{C}$ in $200{ }^{\circ} \mathrm{C}$ increments, then analyzed via TGA, NMR, XPS, TEM/SEM and PXRD to probe the physical properties of the $\mathrm{Al}_{4} \mathrm{C}_{3}-\mathrm{CDC}$. During chlorination, two distinct layers are formed in the bed at etching temperatures of $300{ }^{\circ} \mathrm{C}$ and 500 ${ }^{\circ} \mathrm{C}$, the top layer is black with areas displaying a thin white residue, and the bottom layer is unreacted carbide. SEM-EDS (Table S2) suggests that white material on the $\mathrm{Al}_{4} \mathrm{C}_{3}-\mathrm{CDC}$ is an amorphous aluminum oxide, based on the aluminum and oxygen content observed in EDS. Material etched at 700 and $900{ }^{\circ} \mathrm{C}$ for $1 \mathrm{~h}$ display a homogenous sample with no distinguishable layering. These differences are likely due to changes in intermolecular diffusion in the bed with an increase in etching temperature. In order to characterize the $\mathrm{Al}_{4} \mathrm{C}_{3}$-CDC the two layers underwent a physical separation, if a heterogeneous sample was observed to remove the unreacted carbide portion.

TGA was performed on $\mathrm{Al}_{4} \mathrm{C}_{3}-\mathrm{CDC}$ samples that were produced at $300,500,700$ and $900{ }^{\circ} \mathrm{C}$ for 1 hour to observe the amount of residual aluminum that remained in the sample after chlorination. These temperatures were chosen to receive a broad overview of etching temperature effects on metal content as well as to have a comparison to fully etched samples in literature.[38, 39, 42] Figure 1 reports the effect of temperature on residual metal content. At 300 ${ }^{\circ} \mathrm{C}, 18 \%$ residual aluminum remains after etching. As the etching temperature is increased to 500 ${ }^{\circ} \mathrm{C}$ a steep drop in metal content is observed. This drastic drop in residual aluminum can be attributed to faster diffusion of gaseous species through the sample with increased temperature as

*Corresponding author. Tel: (404) 894-5254. E-mail: krista.walton@ chbe.gatech.edu (Krista Walton) 
well as a shift to the smaller monomeric chloride that will have fewer diffusional limitation while traveling through the porous-carbon structure. Therefore, at lower etching temperatures, where the dimer is present in larger quantities at equilibrium and where the pore size is small, which will be examined later in this paper, the amount of metal removal will be reduced for the same etching times.

Also contributing to changes in residual metal trends is the presence of carbon structures, which begin to form at an appreciable rate in the samples etched at 700 and $900{ }^{\circ} \mathrm{C}$ seen by TEM and PXRD, causing diffusion limitations and pore restructuring. This could potentially slow down the diffusion path of both the monomer and dimer species causing less of a drastic drop in metal content from etching temperatures of $500-900{ }^{\circ} \mathrm{C}$, compared to those seen from $300-500{ }^{\circ} \mathrm{C}$. The lowest metal content is $6 \%$ for $\mathrm{Al}_{4} \mathrm{C}_{3}-\mathrm{CDC}-900-1 \mathrm{~h}$, showing that sample composition can be tuned to be more carbon based simply by increasing etching temperature while maintaining etching time.

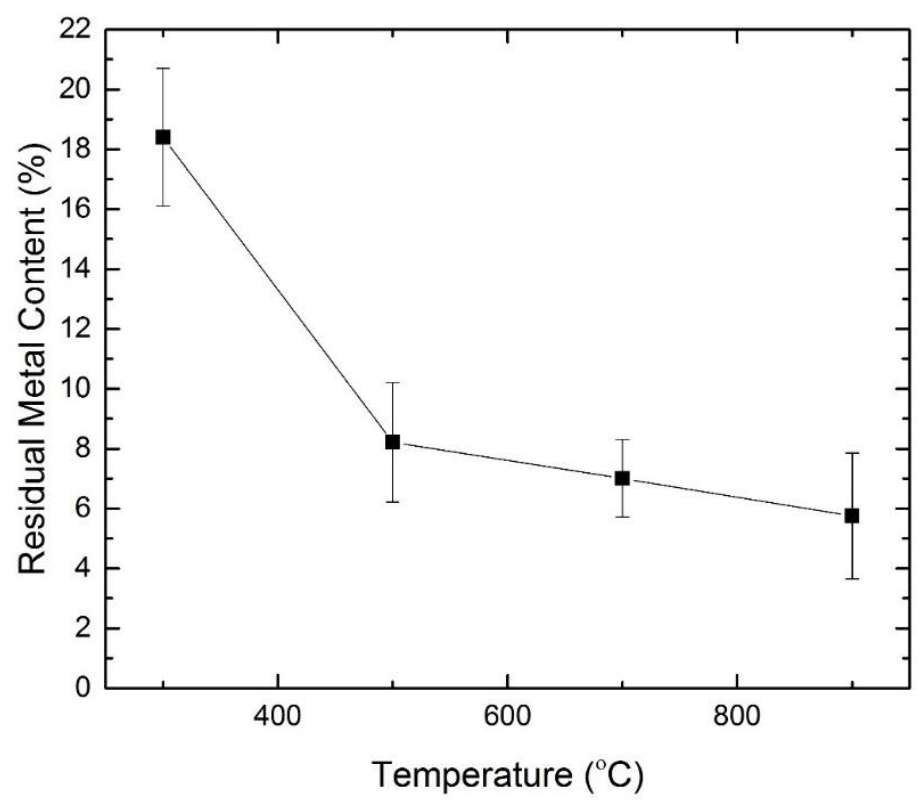

Figure 1. TGA data for residual metal content in the Al-CDC after 1 hour of etching with $\mathrm{Cl}_{2}$ in a temperature range of $300-900{ }^{\circ} \mathrm{C}$ *Corresponding author. Tel: (404) 894-5254. E-mail: krista.walton@ chbe.gatech.edu (Krista Walton) 
Chlorination time also has an effect on the residual metal content. To investigate the time dependence, two time trials were run; the chlorination times were varied from 0-6 h at 300 and $500{ }^{\circ} \mathrm{C}$, these temperatures were chosen due to their high metal content and the significant drop in residual metal between the two, which is not as severe at other $200{ }^{\circ} \mathrm{C}$ jumps. Figure 2 depicts a decrease in residual metal as time increases for both etching temperatures. Unreacted $\mathrm{Al}_{4} \mathrm{C}_{3}$ is designated as $100 \%$ residual metal at an etching time of 0 . At $500{ }^{\circ} \mathrm{C}$, there is more of a significant drop off in the first hour of etching than seen at $300{ }^{\circ} \mathrm{C}$ due to more monomeric species being present at the higher temperature and more energy in the system for diffusion. The residual metal at higher etching times of 4 and $6 \mathrm{~h}$ is believed to be due to trapped metal species in the sample that are not easily extracted due to the formation of carbon structures or aggregation of metal based species. Note that 4 and $6 \mathrm{~h}$ were arbitrary times used to show that with extended periods of etching, metal content can still be observed in the porous-carbon structure, this result is briefly touched on in literature for "fully etched" materials.[38] To remove this material thought to be stuck in the pores after thorough etching, annealing has been shown to be an effective method in other investigations.[46]
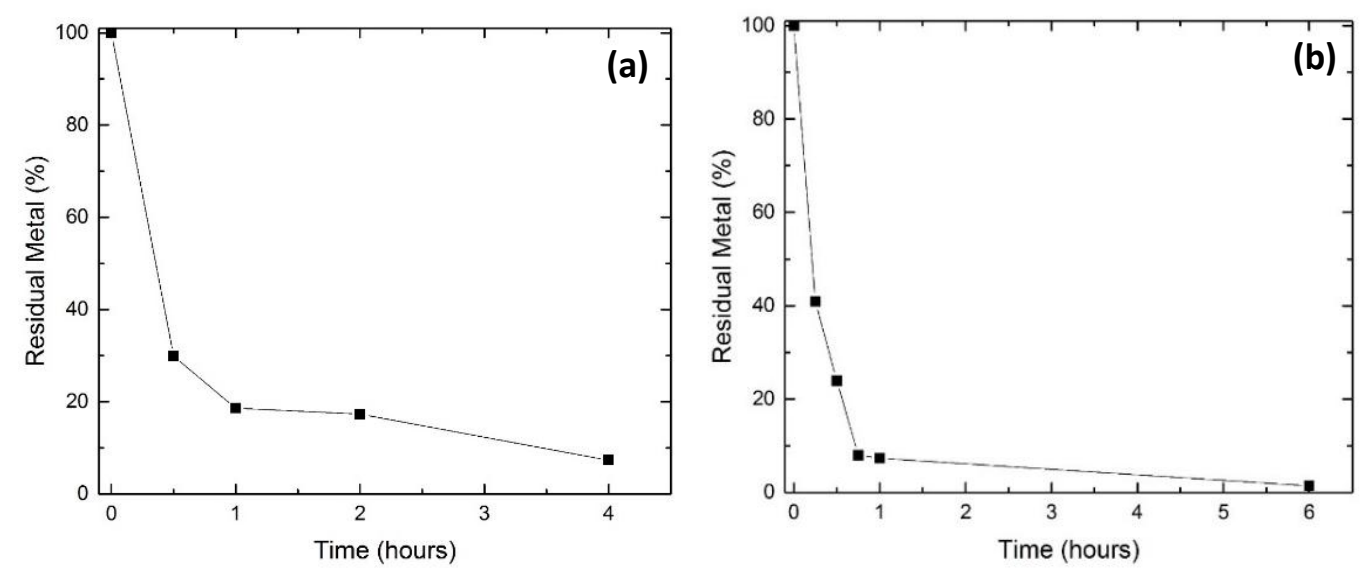

Figure 2. TGA results for time trials of (a) $300{ }^{\circ} \mathrm{C}$ and (b) $500{ }^{\circ} \mathrm{C}$ samples in terms residual metal.

\subsection{Form of metal content in $\mathrm{Al}_{4} \mathrm{C}_{3}-\mathrm{CDC}$}

*Corresponding author. Tel: (404) 894-5254. E-mail: krista.walton@ chbe.gatech.edu (Krista Walton) 
The most conventional mechanism for CDC formation follows a core-shell model. This defines a mechanism where the carbide particle is etched from the outside forming a carbide core until complete etching is achieved. This is also termed layer-by-layer extraction.[47] However, $\mathrm{Al}_{4} \mathrm{C}_{3}-\mathrm{CDC}$ appears to possess a slightly altered mechanism. This is suggested by examining the partially etched samples using TEM. Instead of a carbide core, the residual aluminum detected in $\mathrm{Al}_{4} \mathrm{C}_{3}-\mathrm{CDCs}$ is in the form of aluminum based nanoparticles. It should be noted that at no point during this investigation were the nanoparticles determined to be elemental aluminum. Figure 3 depicts the TEM images for samples prepared at 300, 500, 700, and $900{ }^{\circ} \mathrm{C}$ for $1 \mathrm{~h}$. As the temperature increases, the observed number of nanoparticles decreases; this observation correlates with TGA results. The form of the nanoparticles is also altered with increased temperature. At an etching temperature of $300{ }^{\circ} \mathrm{C}$ nanoparticles are $2-10 \mathrm{~nm}$ in size, while increasing etching temperature to $500{ }^{\circ} \mathrm{C}$ reveals aggregates a magnitude larger in size. Supporting information for these aggregates can be seen in Figures S12-S14 Once the etching temperature reaches $700{ }^{\circ} \mathrm{C}$ crystalline structures are observed in TEM, as depicted in Figure 3c. Table 1 shows that the materials depicted in Figure 3 consist of aluminum, chlorine and oxygen. EDS for $\mathrm{Al}_{4} \mathrm{C}_{3}-\mathrm{CDC}-500-1 \mathrm{~h}$ was not taken for the displayed image, other EDS indicate the same trend of $\mathrm{Al}, \mathrm{O}$, and $\mathrm{Cl}$ elements. Note that the high amounts of carbon content is from the grid and the sample itself while the copper content is from the grid alone. Although the reaction mechanism cannot be directly determined from this data, one theory suggests that $\mathrm{AlCl}_{3}$ is formed during the etching process and is either trapped in the pores or by carbon structures. At the same time an oxygen source, either from oxygen directly involved in the carbide lattice or trace amounts of water in the carbide or chlorine cylinder provides an oxidizing agent. It has been shown in literature that anhydrous aluminum chloride converts to aluminum oxide when in *Corresponding author. Tel: (404) 894-5254. E-mail: krista.walton@ chbe.gatech.edu (Krista Walton) 
the presence of chlorine gas and an oxidizing agent.[29] This process will allow for the aluminum based nanoparticles to contain both chlorine and oxygen elements.

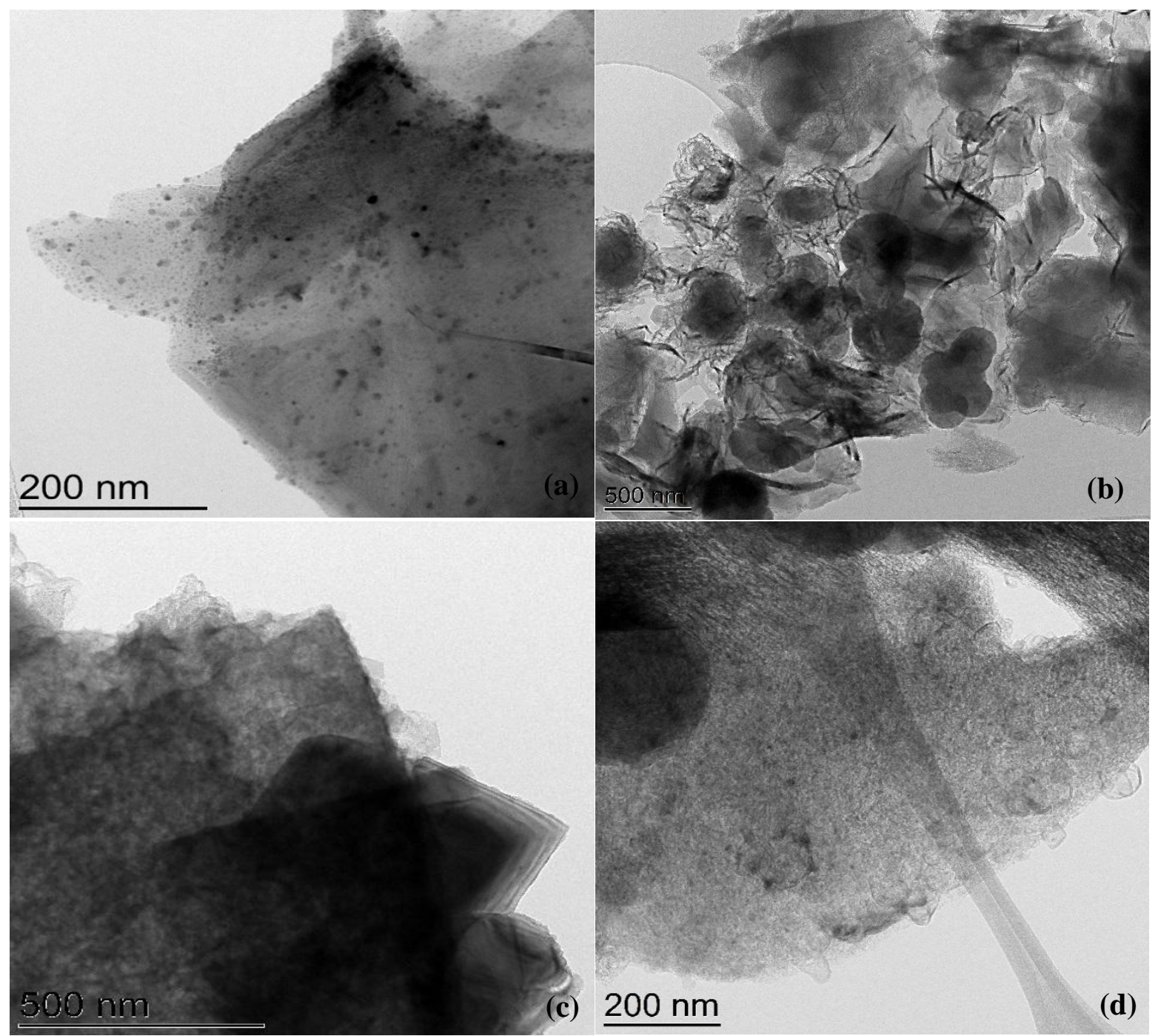

Figure 3. - TEM Images of $\mathrm{Al}_{4} \mathrm{C}_{3}$-CDC: (a) 300-1h, (b) 500-1h (c) 700-1h and (d) 900-1h

Table 1: EDS Results from points taken from Figure 3 Images

\begin{tabular}{llll}
\hline Species & Element & Weight \% & Atomic \% \\
\hline $\mathrm{Al}_{4} \mathrm{C}_{3}-300-1 \mathrm{~h}$ & $\mathrm{C}$ & 42.41 & 64.84 \\
& $\mathrm{O}$ & 8.06 & 9.26 \\
& $\mathrm{Al}$ & 16.4 & 11.16 \\
& $\mathrm{Cl}$ & 22.53 & 11.67 \\
& $\mathrm{Cu}$ & 10.58 & 3.05 \\
\hline $\mathrm{Al}_{4} \mathrm{C}_{3}-700-1 \mathrm{~h}$ & $\mathrm{C}$ & 22.11 & 45.72 \\
& $\mathrm{O}$ & 13.5 & 20.95
\end{tabular}

*Corresponding author. Tel: (404) 894-5254. E-mail: krista.walton@ chbe.gatech.edu (Krista Walton) 


\begin{tabular}{llll} 
& $\mathrm{Al}$ & 14.95 & 13.76 \\
& $\mathrm{Cl}$ & 0.76 & 0.53 \\
& $\mathrm{Cu}$ & 48.66 & 19.01 \\
\hline $\mathrm{Al}_{4} \mathrm{C}_{3}-900-1 \mathrm{~h}$ & $\mathrm{C}$ & 87.07 & 95.48 \\
& $\mathrm{O}$ & 2.46 & 2.02 \\
& $\mathrm{Al}$ & 0.22 & 0.11 \\
& $\mathrm{Cl}$ & 1.52 & 0.56 \\
& $\mathrm{Cu}$ & 8.7 & 1.8 \\
\hline
\end{tabular}

Clusters on the surface of materials etched at 500 and $700{ }^{\circ} \mathrm{C}$ for $1 \mathrm{~h}$ were observed in SEM. Figure 4 shows that there are aluminum based (Table 2) aggregates that appear on the sample surface attached to carbon artifacts emerging from the bulk. These particles are approximately $100 \mathrm{~nm}$ in diameter. These clusters may be forming when aluminum chloride species extracted during chlorination pass the surface and utilize the protruding carbon artifacts as nucleation centers allowing them to remain at certain etching temperatures. This evidence along with dangling particles seen in Figure $3 \mathrm{a}$ and $3 \mathrm{c}$ demonstrates that there are accessible particles on the surface of the partially etched $\mathrm{Al}_{4} \mathrm{C}_{3}-\mathrm{CDC}$ samples. In theory these surface particles can be accessed and tuned for further applications of adsorption, catalysis, and altering electrical properties of the $\mathrm{Al}_{4} \mathrm{C}_{3}-\mathrm{CDC}$.

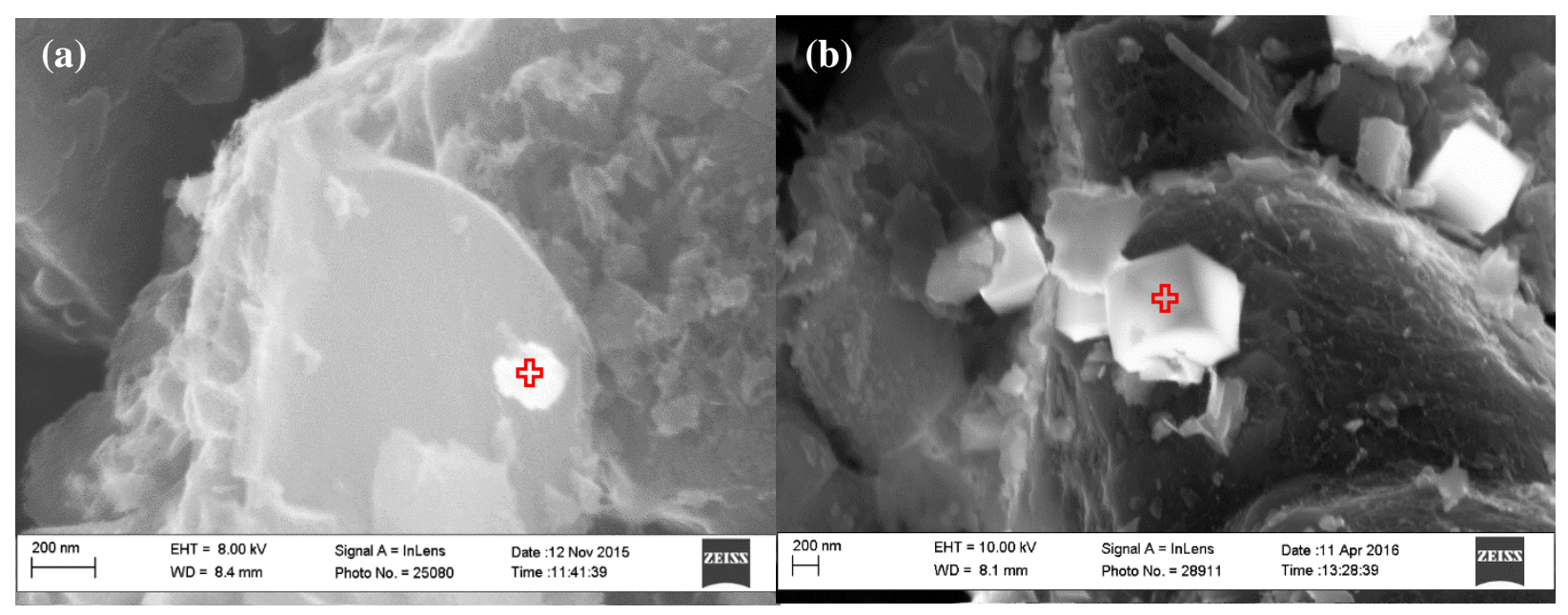

Figure 4. - SEM Images of (a) $500{ }^{\circ} \mathrm{C}$ (b) $700{ }^{\circ} \mathrm{C}$ \& EDS analysis location

*Corresponding author. Tel: (404) 894-5254. E-mail: krista.walton@ chbe.gatech.edu (Krista Walton) 
Table 2: EDS on clustered material seen on $\mathrm{Al}_{4} \mathrm{C}_{3}-\mathrm{CDC}-500-1 \mathrm{~h}$

\begin{tabular}{llll}
\hline Species & Element & Weight \% & Atomic \% \\
\hline $\mathrm{Al}_{4} \mathrm{C}_{3}-500-1 \mathrm{~h}$ & $\mathrm{C}$ & 41.33 & 53.94 \\
& $\mathrm{O}$ & 31.59 & 30.95 \\
& $\mathrm{Al}$ & 22.60 & 13.13 \\
& $\mathrm{Cl}$ & 4.48 & 1.98 \\
\hline $\mathrm{Al}_{4} \mathrm{C}_{3}-700-1 \mathrm{~h}$ & $\mathrm{C}$ & 32.36 & 45.82 \\
& $\mathrm{O}$ & 26.68 & 28.36 \\
& $\mathrm{Al}$ & 40.95 & 25.81 \\
\hline
\end{tabular}

3.3. ${ }^{27} \mathrm{Al}$ MAS NMR of the residual aluminum content

${ }^{27} \mathrm{Al}$ solid-state NMR can monitor the chemical identity of species present after etching at various temperatures. As a quadrupolar nucleus, with nuclear spin quantum number $I=5 / 2$, the local site symmetry can be observed in many instances in the lineshape for a specific quadrupolar broadened ${ }^{27} \mathrm{Al}$ resonance, depending on the local chemical environment. In fact, such lineshapes are seen in the structure of the $\mathrm{Al}_{4} \mathrm{C}_{3}$ starting material, published previously [36], which consists of two quadrupolar resonances corresponding to the two 4-coordinate aluminum sites in the crystal structure, both with quadrupolar asymmetry values $\left(\eta_{\mathrm{Q}}\right)$ of 0.0 and quadrupolar coupling $\left(\mathrm{C}_{\mathrm{Q}}\right)$ values of 15.58 and $15.83 \mathrm{MHz}$ (data not shown).[48]

The ${ }^{27} \mathrm{Al}$ solid-state magic-angle spinning (MAS) NMR of the etched $\mathrm{Al}_{4} \mathrm{C}_{3}-\mathrm{CDC}$ samples reveals significant chemical changes as the reaction proceeds, both as a function of temperature and etching time, shown in Figures 5-7 with NMR parameters given in Table 3. The spectrum of the $\mathrm{Al}_{4} \mathrm{C}_{3}$-CDC sample etched at $300{ }^{\circ} \mathrm{C}$ for 1 hour (Figure 5a) has a quadrupolar lineshape ("Q MAS 1/2") centered at approximately $57 \mathrm{ppm}$ that appears similar to that of the $\mathrm{Al}_{4} \mathrm{C}_{3}$ "parent" compound, and is flanked by a resonance (at low frequency) at a chemical shift with a peak near $7.6 \mathrm{ppm}$ consistent with a 6-coordinate aluminum site. This 6-coordinate site

*Corresponding author. Tel: (404) 894-5254. E-mail: krista.walton@ chbe.gatech.edu (Krista Walton) 
has been fit to a lineshape with a Czjzek distribution, arising from a distribution of quadrupolar environments, commonly observed for amorphous aluminum oxide. [49-51]

Table 3. $-{ }^{27} \mathrm{Al}$ NMR parameters of $\mathrm{Al}_{4} \mathrm{C}_{3}$-CDCs spectra. All values correspond to lineshapes modeled in Dmfit[38]. Dmfit can accommodate different lineshape models: Gaussian is the conventional lineshape, Czjzek is a distribution of quadrupolar environments, Q MAS $1 / 2$ refers to a model of the central transition only with "infinite spinning speed" assumed, Quad $1^{\text {st }}$ is a model of a $1^{\text {st }}$-order quadrupolar MAS spinning sideband pattern.

\begin{tabular}{|c|c|c|c|c|}
\hline Sample & Fit & $\begin{array}{c}\delta_{\text {iso }} \text { Isotropic Chemical } \\
\text { Shift }(\mathrm{ppm})\end{array}$ & $\mathrm{C}_{\mathrm{Q}}(\mathrm{MHz})$ & $\eta_{\mathrm{Q}}$ \\
\hline $300{ }^{\circ} \mathrm{C}-1 \mathrm{hr}$ & Czjzek & 7.6 & 7.7 & - \\
\hline & Gaussian & 94.4 & - & - \\
\hline & Gaussian & 100.6 & - & 0.0 \\
\hline & "Q MAS 1/2" & (centered 57ppm) & 14.5 & - \\
\hline $500{ }^{\circ} \mathrm{C}-1 \mathrm{hr}$ & Czjzek & -0.9 & 10.5 & 0.0 \\
\hline & "Q MAS 1/2" & 74.6 & 1.9 & - \\
\hline $500{ }^{\circ} \mathrm{C}-6 \mathrm{hr}$ & Czjzek & -1.9 & - & - \\
\hline & Gaussian & 1.2 & - & 0.0 \\
\hline $700{ }^{\circ} \mathrm{C}-1 \mathrm{hr}$ & Gaussian & -2.7 & 2.38 & - \\
\hline & "Quad 1 & 14.2 & & \\
\hline
\end{tabular}

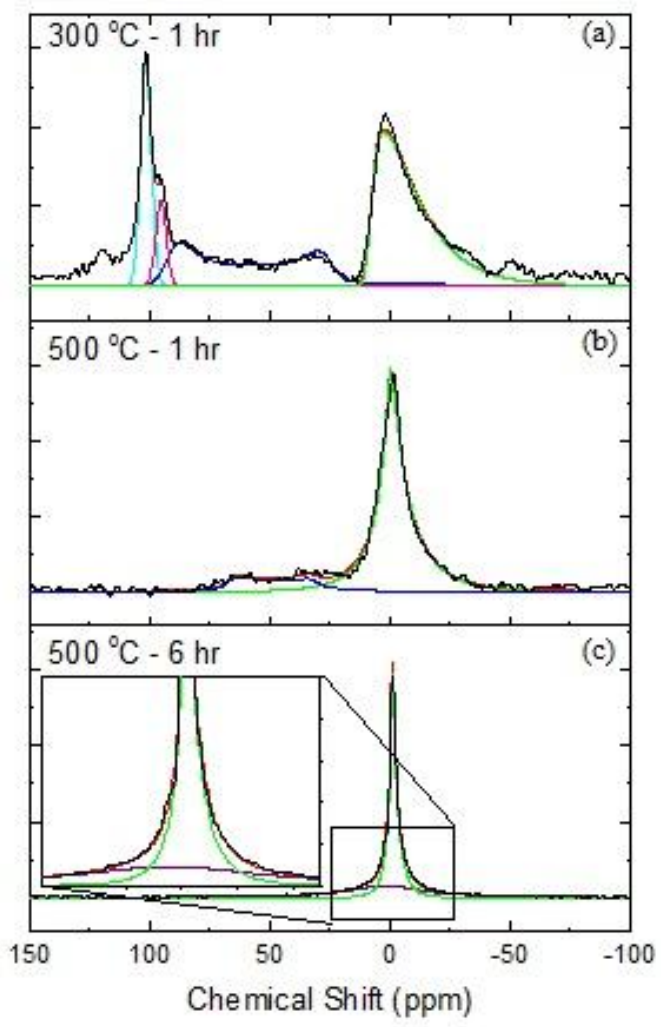

*Corresponding author. Tel: (404) 894-5254. E-mail: krista.walton@ chbe.gatech.edu (Krista Walton) 
Figure 5. $-{ }^{27} \mathrm{Al}$ MAS NMR data of $\mathrm{Al}_{4} \mathrm{C}_{3}-\mathrm{CDC}$ : a) $300{ }^{\circ} \mathrm{C}$ for $1 \mathrm{hr}$, b) $500{ }^{\circ} \mathrm{C}$ for $1 \mathrm{hr}$, and c) $500{ }^{\circ} \mathrm{C}$ for $6 \mathrm{hrs}$.

A separate HMQC experiment (Figure 6) demonstrates that this 6-coordinate site is closely coupled to protons, which allows us to assign this resonance to $\mathrm{Al}(\mathrm{OH})_{3}$. On the high frequency side of the "Q MAS 1/2" lineshape, there are two sharp resonances in a region where 4coordinate aluminum is typically found. These solid-state resonances are both narrow (FWHM $800 \mathrm{~Hz})$, and the chemical shifts at 94.4 and $100.6 \mathrm{ppm}$ are consistent with different $\mathrm{AlCl}_{\mathrm{x}}(\mathrm{OH})_{\mathrm{y}}$ species, that resonate at 103 to 94 ppm.[52], or potentially with that of $\mathrm{Al}_{2} \mathrm{Cl}_{6}$ (a "dimer" of $\mathrm{AlCl}_{3}$ ). (The dimer is known to be a gaseous or molten species, that is consistent with a narrow linewidth for these 4-coordinate sites but would not be expected to persist in a solid-state experiment, at ambient conditions, as seen here.) However, these results suggest the amorphous and porous carbon host may allow for $\mathrm{Al}_{2} \mathrm{Cl}_{6}$ to reside in the pores. The spectrum of the sample prepared at $500{ }^{\circ} \mathrm{C}$ for 1 hour of etching (Figure 5b) looks remarkably different from that of the $300{ }^{\circ} \mathrm{C}$ sample. It has a small residual quadrupolar-broadened lineshape (Q MAS 1/2) centered at in the middle region of the spectrum (shown fit to a quadrupolar-broadened resonance, with $\eta_{\mathrm{Q}}=$ 0.0 and $\mathrm{C}_{\mathrm{Q}}=10.5 \mathrm{MHz}$ ), presumably sites similar to that of the remaining parent $\mathrm{Al}_{4} \mathrm{C}_{3}$. $\mathrm{A}$ resonance for a 6-coordinate aluminum is present, peaked at $-0.9 \mathrm{ppm}$ and with a Czjzek distribution. Comparison to the $500{ }^{\circ} \mathrm{C}$ 6-hour etched sample, shows the disappearance of the resonance from the parent material, and only a more symmetric pair of resonances is found-a sharp resonance (with a relatively narrow Czjzek distribution) at $-1.9 \mathrm{ppm}$ superimposed on a broad resonance centered at $1.2 \mathrm{ppm}$. It is difficult to assign these specifically, as the porous carbon host is increasingly paramagnetic, however the sharp resonance at $-1.9 \mathrm{ppm}$ is consistent *Corresponding author. Tel: (404) 894-5254. E-mail: krista.walton@ chbe.gatech.edu (Krista Walton) 
with similar spectra of $\mathrm{Al}\left(\mathrm{H}_{2} \mathrm{O}\right)_{6}{ }^{3+}$, which is formed with air exposure of the samples prior to measurement. .

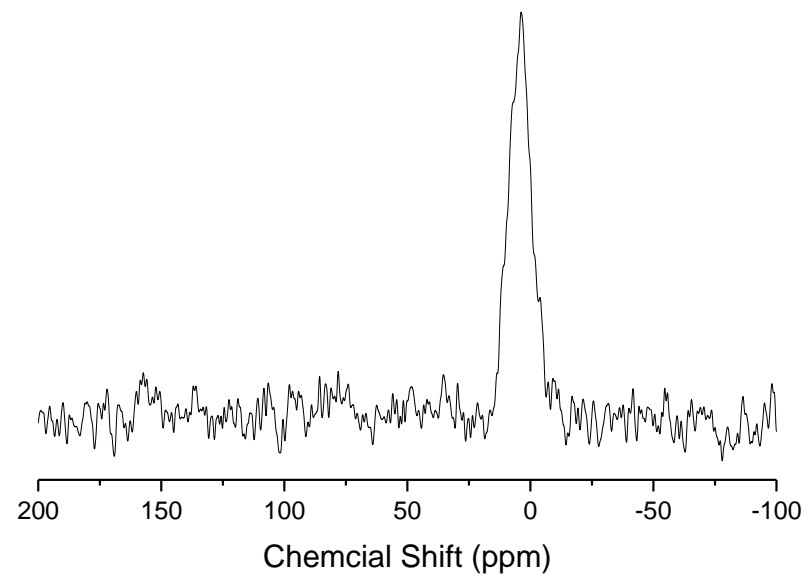

Figure 6. $-{ }^{27} \mathrm{Al}$ MAS NMR data of $\mathrm{Al}_{4} \mathrm{C}_{3}$-CDC-300-1h using a double resonance HMQC sequence. The only peak that has nearby hydrogens is the peak around $0 \mathrm{ppm}$.

Finally, in Figure 7 is a ${ }^{27} \mathrm{Al}$ MAS NMR spectrum of the Al-CDC materials etched at 700 ${ }^{\circ} \mathrm{C}$. For the two 6-coordinate resonances observed, the one at $14.2 \mathrm{ppm}$ has a large manifold of spinning sidebands, which we assign to $\alpha-\mathrm{Al}_{2} \mathrm{O}_{3}$. [53] Such a manifold of sidebands maps out the lineshape, which is consistent with a crystallographically well-defined state. Fitting of the spectrum in Figure 7 was done in Dmfit and is consistent with parameters previously determined for $\alpha-\mathrm{Al}_{2} \mathrm{O}_{3} \cdot[50,54]$ PXRD indicates the presence of $\alpha-\mathrm{Al}_{2} \mathrm{O}_{3}$, which we confirm by NMR, but there is also a small amount of residual amorphous aluminum oxide in the $700{ }^{\circ} \mathrm{C}$ sample, evidenced by the peak at $-2.7 \mathrm{ppm}$ (that does not possess enough long-range order to give PXRD reflections). We cannot exclude other $\mathrm{AlCl}_{\mathrm{x}}(\mathrm{OH})_{\mathrm{y}}$ or $\mathrm{AlCl}_{\mathrm{x}} \mathrm{O}_{\mathrm{y}}$ species from some of the unassigned peaks in Figures 5 and 7. For example, previous literature has assigned 4-coordinate resonances of $\left[\mathrm{AlCl}_{4}\right]^{-}$through $\left[\mathrm{Al}(\mathrm{OH})_{4}\right]^{-}$in the chemical shift range of 103 to $79 \mathrm{ppm}$, respectively.[52] Further model compounds would be needed to assign such resonances with certainty in the $\mathrm{Al}_{4} \mathrm{C}_{3}-\mathrm{CDC}$ system.

*Corresponding author. Tel: (404) 894-5254. E-mail: krista.walton@ chbe.gatech.edu (Krista Walton) 

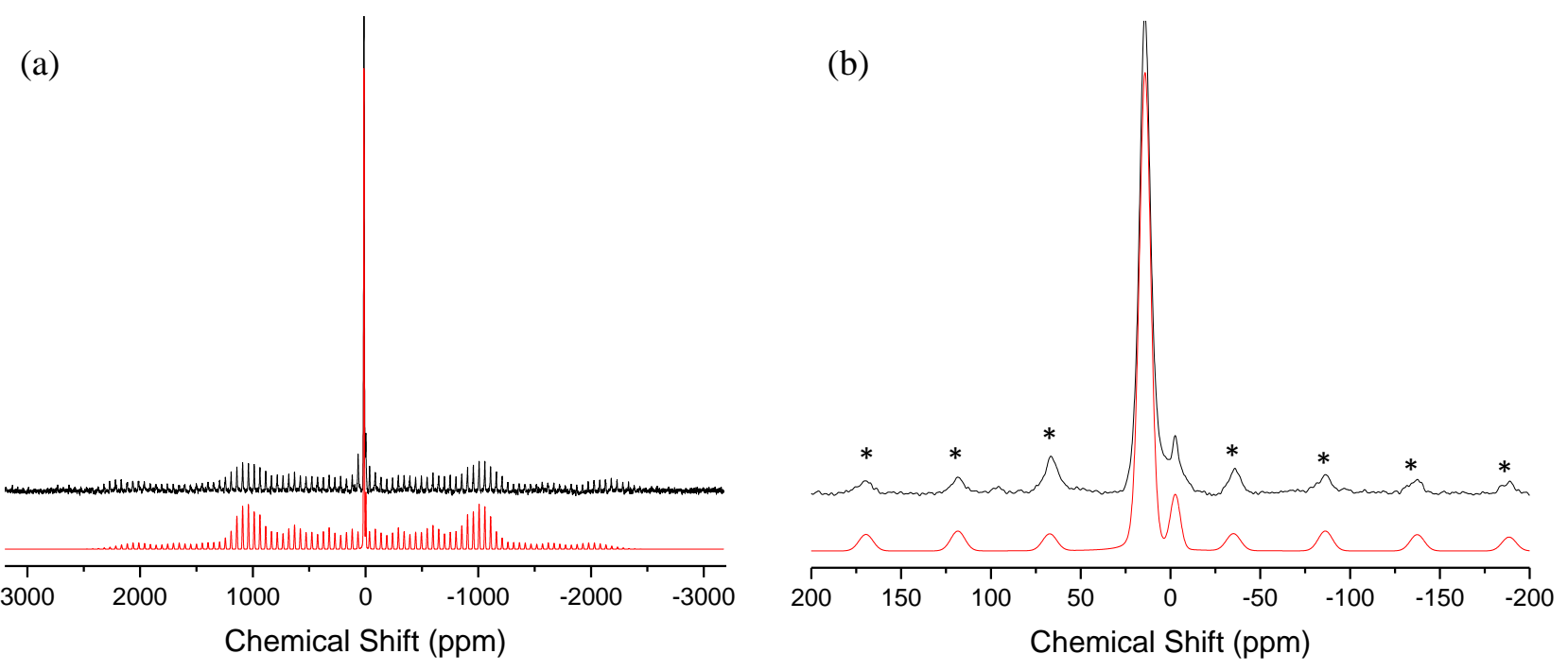

Figure 7: (a) ${ }^{27} \mathrm{Al}$ MAS NMR on $\mathrm{Al}_{4} \mathrm{C}_{3}-\mathrm{CDC}-700-1 \mathrm{~h}$ spinning at $8 \mathrm{kHz}$ (shown in black) including a fit (shown in red) utilizing previous parameters determined for $\alpha-\mathrm{Al}_{2} \mathrm{O}_{3}, \mathrm{C}_{\mathrm{Q}}=2.38$ $\mathrm{MHz}$ and $\eta_{\mathrm{Q}}=0.0 .[54]$ On a smaller scale (b) we can see the hydrogen-bearing aluminum peak, at $-2.7 \mathrm{ppm}$, has almost been completely removed and the emergence of a new peak centered at $14.2 \mathrm{ppm}$, which corresponds to $\alpha-\mathrm{Al}_{2} \mathrm{O}_{3}$. $*$ refers to spinning sidebands.

Finally, the ${ }^{13} \mathrm{C}$ spectra are wholly uninformative across this series, largely because the carbon rapidly develops paramagnetic centers with etching. It is worthwhile to note that spinning the samples at etching temperatures of $500{ }^{\circ} \mathrm{C}$ and higher was difficult, owing to the carbon becoming conductive (see section 3.5) and causing resistance to MAS from the paramagnetic sites creating "drag” or impedance to spinning in a magnetic field.

3.4. XPS surface analysis of samples etched at 300 and $500^{\circ} \mathrm{C}$ for $1 \mathrm{~h}$ XPS was utilized to examine the environment of aluminum and chlorine on the surface of $\mathrm{Al}_{4} \mathrm{C}_{3}$-CDC-300-1h and $\mathrm{Al}_{4} \mathrm{C}_{3}-\mathrm{CDC}-500-1 \mathrm{~h}$ samples. The $\mathrm{Al}_{4} \mathrm{C}_{3}$ precursor showed an $\mathrm{Al} 2 \mathrm{p}$ peak at $73.34 \mathrm{eV}$ which has been assigned to the carbide in literature [55]. As expected, samples that

*Corresponding author. Tel: (404) 894-5254. E-mail: krista.walton@ chbe.gatech.edu (Krista Walton) 
were etched in this investigation no longer expressed a peak at $73.34 \mathrm{eV}$, indicating aluminum content on the surface was not in its original carbide form after etching. High resolution aluminum scans reveal aluminum in two different environments, at binding energies of 74.82 and $76.58 \mathrm{eV}$ on the surface of $\mathrm{Al}_{4} \mathrm{C}_{3}-\mathrm{CDC}-300-1 \mathrm{~h}$ as visualized in Figure 8. The Al2p peak at $74.82 \mathrm{eV}$ was assigned to $\mathrm{Al}(\mathrm{OH})_{3}$ which agrees with $\mathrm{NMR}$ data, and the peak at $76.58 \mathrm{eV}$ was attributed to $\mathrm{AlCl}_{3}$ and $\mathrm{Al}-\mathrm{O}$ matrix with chlorine incorporated in its structure. These assignments are supported by the $\mathrm{Cl} 2 \mathrm{p}$ doublet at $198.48 \mathrm{eV}$ seen in the high resolution chlorine spectra and O1s peaks at 531.82 in the high resolution oxygen spectra assigned to chlorine incorporated into an $\mathrm{Al}-\mathrm{O}$ matrix and $\mathrm{Al}(\mathrm{OH})_{3}$ respectively.[56-58] Notably the $\mathrm{Cl} 2 \mathrm{p}$ peak is represented as a $2 \mathrm{p}_{3 / 2}-2 \mathrm{p}_{1 / 2}$ spin pair doublet. Recent work has shown the doublet at 198.48 and $199.98 \mathrm{eV}$ is representative of surface and bulk chlorine incorporated into the Al-O matrix.[56, 59] At a higher binding energy, the chlorine scans show chlorine chemisorbed to $\mathrm{sp}^{2}$ and $\mathrm{sp}^{3}$ carbon with a Cl2p peak at $200.21 \mathrm{eV}$, with the doublet accounting for $62 \%$ of residual chlorine on the surface of $\mathrm{Al}_{4} \mathrm{C}_{3}-\mathrm{CDC}-300-1 \mathrm{~h}$.[60] This result is expected, with a majority of elemental chlorine removed when the material is put under high vacuum. A fractional amount of elemental chlorine is observed to be trapped near the surface of the sample at a binding energy of 202.68 eV. $[60,61]$ Along with the oxygen incorporated into the Al-O matrix, the O1s spectra also demonstrates oxygen functional groups bound to carbon at binding energies of 532.41 and $533.25 \mathrm{eV}$ representing carbonyl, hydroxyl and ether groups. [62] $\mathrm{Al}_{4} \mathrm{C}_{3}-\mathrm{CDC}-500-1 \mathrm{~h}$ displays a more uniform aluminum content on the surface centered around $74.38 \mathrm{eV}$ assigned to $\mathrm{Al}(\mathrm{OH})_{3}$ and $\mathrm{Al}_{2} \mathrm{O}_{3}$ with a small shoulder at a higher binding energy assigned to chlorine in the Al-O matrix supported by the $\mathrm{Cl} 2 \mathrm{p}$ peak at $198.1 \mathrm{eV}$. Residual chlorine content for $\mathrm{Al}_{4} \mathrm{C}_{3}-\mathrm{CDC}-500-$

*Corresponding author. Tel: (404) 894-5254. E-mail: krista.walton@ chbe.gatech.edu (Krista Walton) 
$1 \mathrm{~h}$ was similar to that of $\mathrm{Al}_{4} \mathrm{C}_{3}$-CDC-300-1h samples with the majority of the species chemisorbed to carbon with a fraction of trapped elemental chlorine also detected (S10).
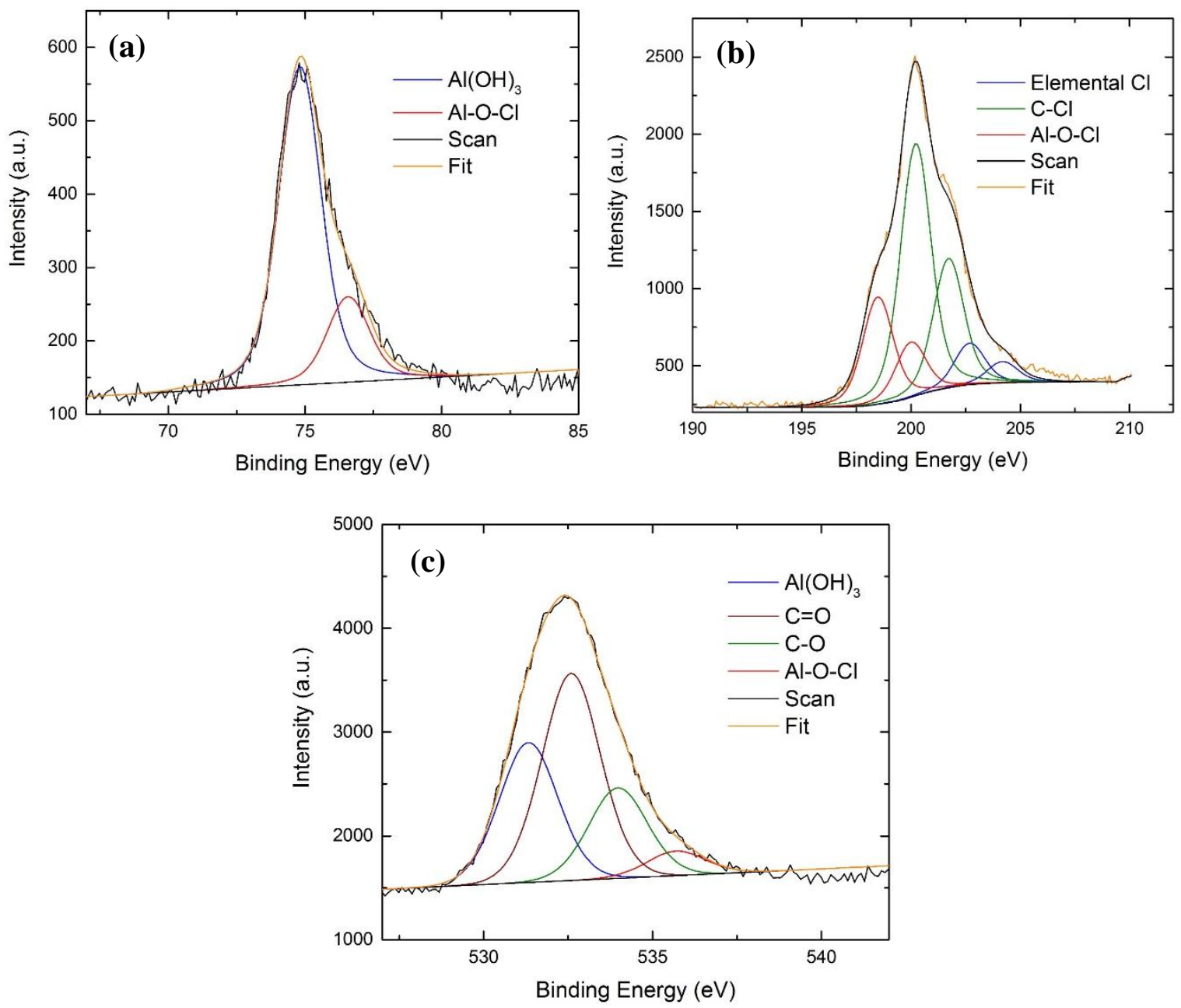

Figure 8: High resolution XPS spectra on $\mathrm{Al}_{4} \mathrm{C}_{3}-\mathrm{CDC}-300-1 \mathrm{~h}$ for (a) Aluminum (b) Chlorine and (c) Oxygen

\subsection{Crystalline structure formation observed via PXRD and TEM}

The etching temperature can also affect the carbon structure, ranging from disordered carbon to graphitic carbon polymorphs. PXRD patterns were obtained for the samples prepared at various temperatures to determine the presence of structured carbon. As seen in Figure 9,

*Corresponding author. Tel: (404) 894-5254. E-mail: krista.walton@ chbe.gatech.edu (Krista Walton) 
samples etched at $300{ }^{\circ} \mathrm{C}$ and $500{ }^{\circ} \mathrm{C}$ exhibit a very small broad [002] peak at a $2 \theta$ value of $26.3^{\circ}$ that is indicative of amorphous carbon. Also seen in $\mathrm{Al}_{4} \mathrm{C}_{3}-\mathrm{CDC}-300-1 \mathrm{~h}$ samples are peaks related to the carbide that was not exposed to chlorine during the chlorination. In contrast, the samples etched at 700 and $900{ }^{\circ} \mathrm{C}$ both show a sharp [002] peak at $26.3^{\circ}$ and [100] peak at $43^{\circ}$ representing parallel stacking of graphitic planes which both suggest highly ordered carbon structures.[63] The PXRD patterns also show no aluminum based crystalline species other than the original carbide for all temperatures, except for $\mathrm{Al}_{4} \mathrm{C}_{3}-\mathrm{CDC}-700-1 \mathrm{~h}$ samples. Seen in the PXRD pattern for the $700{ }^{\circ} \mathrm{C}$ samples are reflections with $2 \theta$ values of (26), (35.2), (37.7), (43), (52.5), (57.46) corresponding to $\alpha-\mathrm{Al}_{2} \mathrm{O}_{3}$. [64, 65] Samples etched for $0.25 \mathrm{~h}$ and $2 \mathrm{~h}$ at $700{ }^{\circ} \mathrm{C}$ also display $\alpha-\mathrm{Al}_{2} \mathrm{O}_{3}$ peaks. The presence of this oxide has been seen in prior work at the reaction temperature of $700{ }^{\circ} \mathrm{C}$ with aluminum chloride in the presence of oxygen and chlorine gas as a catalyst, but was found to be a polymorph of the thermodynamically stable phase, $\kappa-\mathrm{Al}_{2} \mathrm{O}_{3}$.[29] The observed $\alpha-\mathrm{Al}_{2} \mathrm{O}_{3}$ has been shown to be repeatable with multiple runs at the same conditions. It is currently unknown as to why $\alpha-\mathrm{Al}_{2} \mathrm{O}_{3}$ only forms in the temperature window between 500 and $900{ }^{\circ} \mathrm{C}$. It is speculated that for lower etching temperatures there is not adequate energy in the system for the formation of the oxide, and at the higher temperature of $900{ }^{\circ} \mathrm{C}$ any source of oxygen is more thermodynamically favorable in the gas phase and will not allow for a surface based deposition process similar to that of atomic layer deposition of $\mathrm{Al}_{2} \mathrm{O}_{3}$. [66, 67]

*Corresponding author. Tel: (404) 894-5254. E-mail: krista.walton@ chbe.gatech.edu (Krista Walton) 


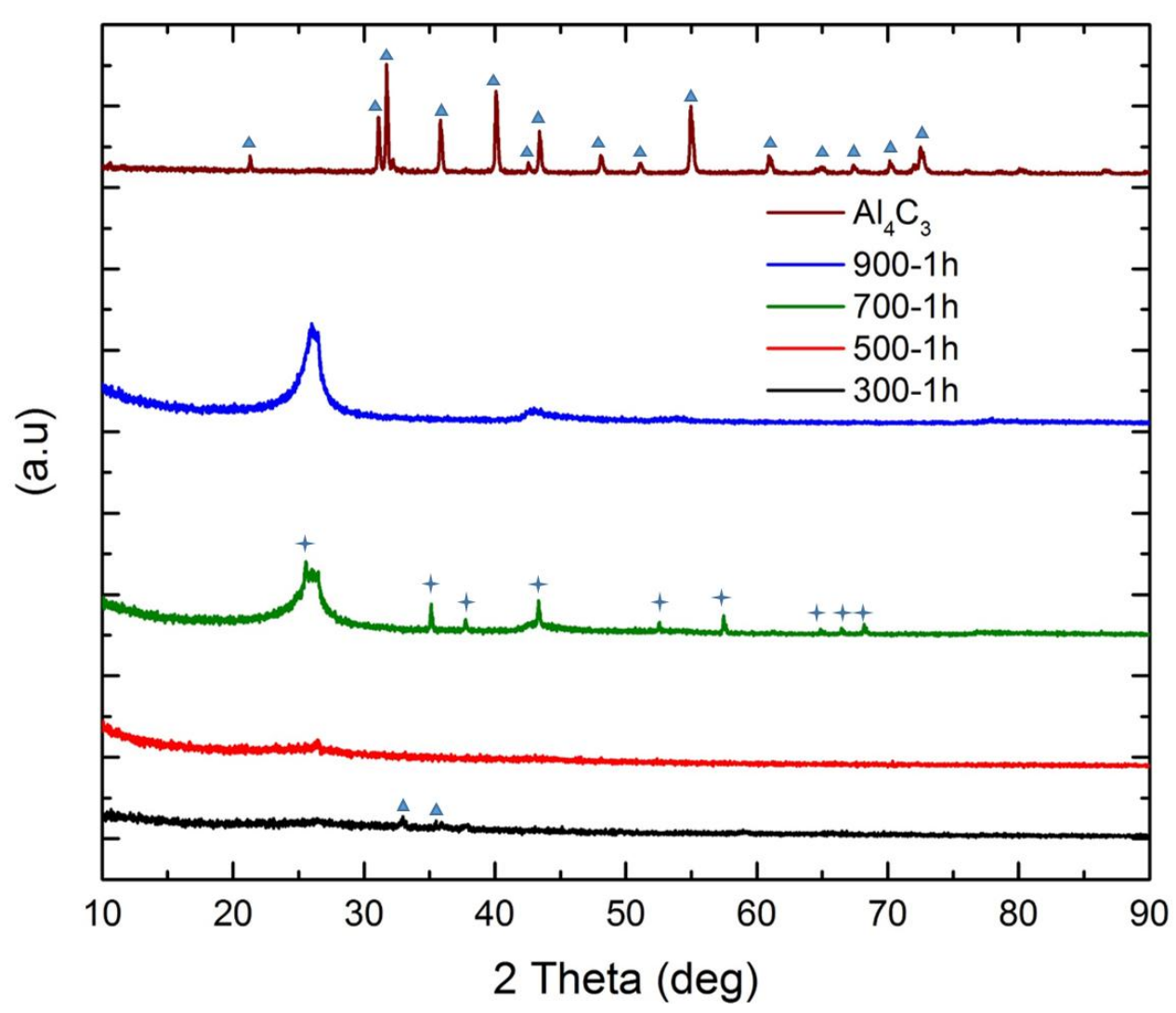

Figure 9. - PXRD patterns of $\mathrm{Al}_{4} \mathrm{C}_{3}$ and samples etched at $300,500,700$ and $900{ }^{\circ} \mathrm{C}$ for $1 \mathrm{hr}$. $+=\alpha-\mathrm{Al}_{2} \mathrm{O}_{3} \quad \Delta=\mathrm{Al}_{4} \mathrm{C}_{3}$

TEM/HRTEM images were taken of the samples to observe and further understand the types of carbon structures forming at different reaction conditions. At low etching temperatures, $300{ }^{\circ} \mathrm{C}$ and $500{ }^{\circ} \mathrm{C}$, mainly amorphous carbon is seen. In select areas for $\mathrm{Al}_{4} \mathrm{C}_{3}-\mathrm{CDC}-500-1 \mathrm{~h}$ graphitic ribbons begin to form, as visualized in Figure 10b. Once the temperature reaches 700 ${ }^{\circ} \mathrm{C}$ graphitic structures, such as turbostratic carbon, carbon nanostructures, carbonaceous microspheres and graphene are observed. The carbon structures observed follow the trends seen in PXRD patterns, which suggest the formation of more ordered carbon structures at increased etching temperatures. The increase in the ordering of carbon is supported by Raman (S15) with increased graphitic characteristics as etching temperature rises. The formation of these graphitic

*Corresponding author. Tel: (404) 894-5254. E-mail: krista.walton@ chbe.gatech.edu (Krista Walton) 
structures has also been detailed in previous studies that have evaluated the complete etching of $\mathrm{Al}_{4} \mathrm{C}_{3}$ at various temperatures.[38, 39, 42]

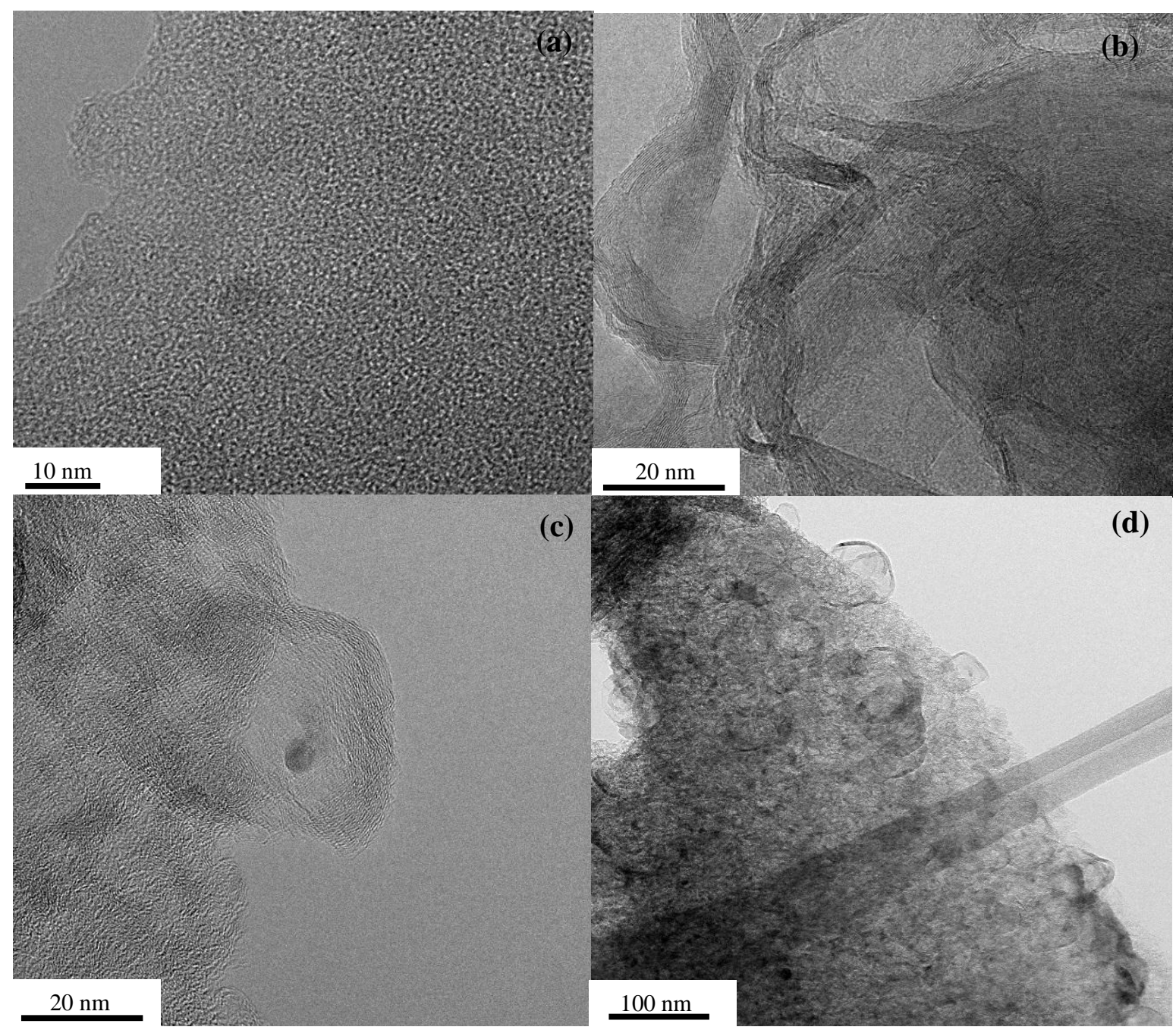

Figure 10. - TEM images of $\mathrm{Al}_{4} \mathrm{C}_{3}$-CDC prepared by etching: (a) $300-1 \mathrm{~h}$ scale bar $10 \mathrm{~nm}$ (b) $500-1 \mathrm{~h} \mathrm{(c)} 700-1 \mathrm{~h}$ and (d) $900-1 \mathrm{~h}$

3.6. Dependence of $\mathrm{Al}_{4} \mathrm{C}_{3}$-CDC Porosity and Surface Area on Reaction Temperature and Time After chlorination, the $\mathrm{Al}_{4} \mathrm{C}_{3}$-CDC samples were analyzed via nitrogen physisorption at 77K, QSDFT was used to determine the resulting effects that time and temperature had on pore size distribution and surface area. Table 3 reports the surface area and pore volume as it changes with sample preparation temperature. An increase in surface area can be seen with the increase in *Corresponding author. Tel: (404) 894-5254. E-mail: krista.walton@ chbe.gatech.edu (Krista Walton) 
etching temperature from 300 to $500{ }^{\circ} \mathrm{C}$, which can be attributed to less residual aluminum present while maintaining a primarily amorphous carbon material. At increased etching temperatures, the effects of carbon rearrangement come into play. As the etching temperature increases, carbon structure formation increases in the samples. The smaller micropores break down and become part of larger mesopores, Table 4 visualizes this trend with a decrease in microporous volume and increase in mesoporous volume as etching temperature increases. Also seen in Table 4, the drastic reduction in micropore volume is accompanied by a reduction in surface area. At higher etching temperatures, structures such as graphite are produced, as seen in previous work, which also results in the reduction of surface area.[42] These trends have also been observed for materials etched at increasing times while keeping temperature constant at either 300 or $500^{\circ} \mathrm{C}$ as depicted in Figure 11.

Table 4: Temperature trial runs corresponding BET surface area $\left(\mathrm{S}_{\text {bet }}\right)$ and pore volume $\left(\mathrm{V}_{\mathrm{p}}\right)$ calculated using QSDFT

\begin{tabular}{llccc}
\hline Sample & $\mathrm{S}_{\text {bet }}\left(\mathrm{m}^{2} \mathrm{~g}^{-1}\right)$ & $\mathrm{V}_{\mathrm{P}}\left(\mathrm{cm}^{3} \mathrm{~g}^{-1}\right)$ & $\mathrm{V}_{\text {Micopores }}\left(\mathrm{cm}^{3} \mathrm{~g}^{-1}\right)$ & $\mathrm{V}_{\text {Mesopores }}\left(\mathrm{cm}^{3} \mathrm{~g}^{-1}\right)$ \\
\hline $\mathrm{Al}_{4} \mathrm{C}_{3}-300-1 \mathrm{~h}$ & 643 & 0.20 & 0.2 & 0.00 \\
$\mathrm{Al}_{4} \mathrm{C}_{3}-500-1 \mathrm{~h}$ & 1126 & 0.53 & 0.4 & 0.13 \\
$\mathrm{Al}_{4} \mathrm{C}_{3}-700-1 \mathrm{~h}$ & 597 & 0.66 & 0.09 & 0.57 \\
$\mathrm{Al}_{4} \mathrm{C}_{3}-900-1 \mathrm{~h}$ & 690 & 1.25 & 0.07 & 1.18 \\
\hline
\end{tabular}

As etching time increases, more residual aluminum is removed from the sample, and the surface area begins to increase. After $1 \mathrm{~h}$ of etching, the rate at which aluminum is taken from the sample is decreased, as depicted earlier via TGA analysis. This slowing, coupled with more time for carbon rearrangement in the sample, leads to a leveling off of surface area and even a slight surface area reduction, as etching time is increased for samples etched at 300 and $500{ }^{\circ} \mathrm{C}$. This

*Corresponding author. Tel: (404) 894-5254. E-mail: krista.walton@ chbe.gatech.edu (Krista Walton) 
reduction is due to the allotment of more time for carbon rearrangement allowing for carbon structures and mesopores to form as previously mentioned and visualized in Figure 13b and 13c.
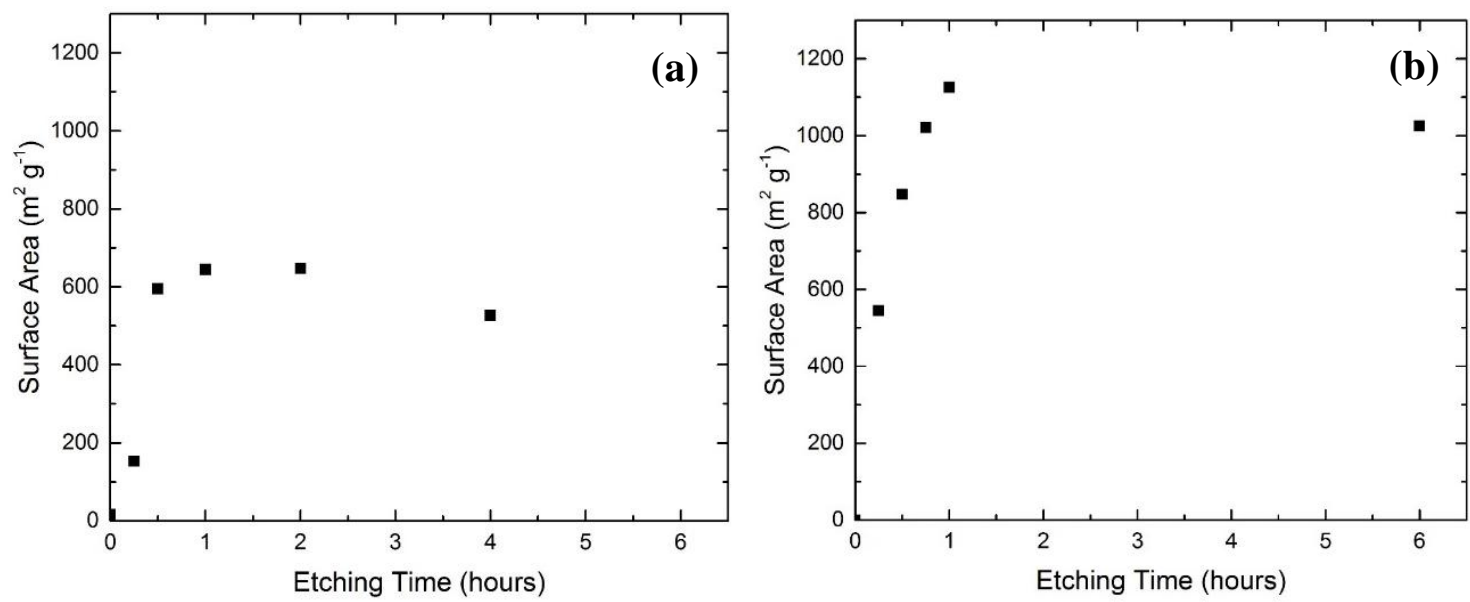

Figure 11. - BET surface areas via $\mathrm{N}_{2}$ adsorption for samples etched at times for (a) $300{ }^{\circ} \mathrm{C}$ and (b) $500{ }^{\circ} \mathrm{C}$

Depending on the characteristics of the sample and the presence of hysteresis in the $\mathrm{N}_{2}$ isotherm, different assumptions were made for the QSDFT analysis in terms of the pore geometry. The pores in samples produced at $300{ }^{\circ} \mathrm{C}$ do not show hysteresis, and pores smaller than $2 \mathrm{~nm}$ were assumed to be slit shaped. Pores for samples etched at 500, 700 and $900{ }^{\circ} \mathrm{C}$ for 1h, which have hysteresis and elements of both micro and mesopores, were assumed to be a mix of slit and cylindrical pores. These assumptions were heavily influenced by the isotherms of the samples as seen in Figure S11. Observed for $\mathrm{Al}_{4} \mathrm{C}_{3}-\mathrm{CDC}-300-1 \mathrm{~h}$ is a type I or pseudo-Langmuir isotherm where there is a sudden halt in adsorption after the knee, which is indicative of the end of micropore contribution to adsorption. Samples etched at $500{ }^{\circ} \mathrm{C}$ for $1 \mathrm{~h}$ also exhibit a type I isotherm with a small hysteresis indicating the presence of mesopores, while 700 and $900{ }^{\circ} \mathrm{C}$ samples both exhibit type IV isotherms.[68] These samples show a large hysteresis which correlates with an appreciable amount of mesoporosity.

*Corresponding author. Tel: (404) 894-5254. E-mail: krista.walton@ chbe.gatech.edu (Krista Walton) 
Following what has already been observed in the field of $\mathrm{CDC}$ 's, $\mathrm{Al}_{4} \mathrm{C}_{3}-\mathrm{CDCs}$ have a narrow pore-size distribution that can be affected by the etching temperature.[9] Figure 12a shows that as chlorination temperature increases, the average pore size increases, and the distribution broadens. This trend can be explained by increased carbon reorganization at higher temperatures, where smaller collectives of micropores begin to form mesopores. $\mathrm{Al}_{4} \mathrm{C}_{3}$-CDC300-1h samples are entirely microporous with a bimodal distribution centered on $0.7 \mathrm{~nm}$ and 1.1 nm. This bimodal behavior can be explained due to two different types of aluminum coordination environments in the carbide precursor, which results in different $\mathrm{Al}-\mathrm{C}$ bond lengths. Therefore, when the heteroatom is removed from the matrix, it will create a slightly different pore for the two types of aluminum atoms extracted.[69] Pore broadening due to carbon rearrangement may also contribute to the different pore sizes observed. It should be noted that the lower limit of nitrogen adsorption is seen at a pore size of $0.7 \mathrm{~nm}$ due to the limitation of pore filling and slow adsorption equilibration. Consequently, pore sizes shown at $0.7 \mathrm{~nm}$ for nitrogen adsorption represent pore sizes $\leq 0.7 \mathrm{~nm}$. $\mathrm{Al}_{4} \mathrm{C}_{3}$-CDC-500-1h materials display both micro and mesopores. The micropores in the sample still show a bimodal distribution centered at slightly higher sizes of 0.9 and $1.2 \mathrm{~nm}$. The mesopores being generated with carbon restructuring are distributed around $3.6 \mathrm{~nm}$. Samples that have been etched at temperatures of 700 and $900{ }^{\circ} \mathrm{C}$ show a combination of micro and mesopores seen at 0.9 and $8.0 \mathrm{~nm}$ respectively. Figures $12 \mathrm{~b}$ and $12 \mathrm{c}$ show that the influence of time on the etching process does not affect the pore size distribution to the degree that temperature does. It can be observed, however, with longer etching times, some carbon restructuring can occur to form slightly larger pores as observed in samples etched at $300^{\circ} \mathrm{C}$ at various times.

*Corresponding author. Tel: (404) 894-5254. E-mail: krista.walton@ chbe.gatech.edu (Krista Walton) 

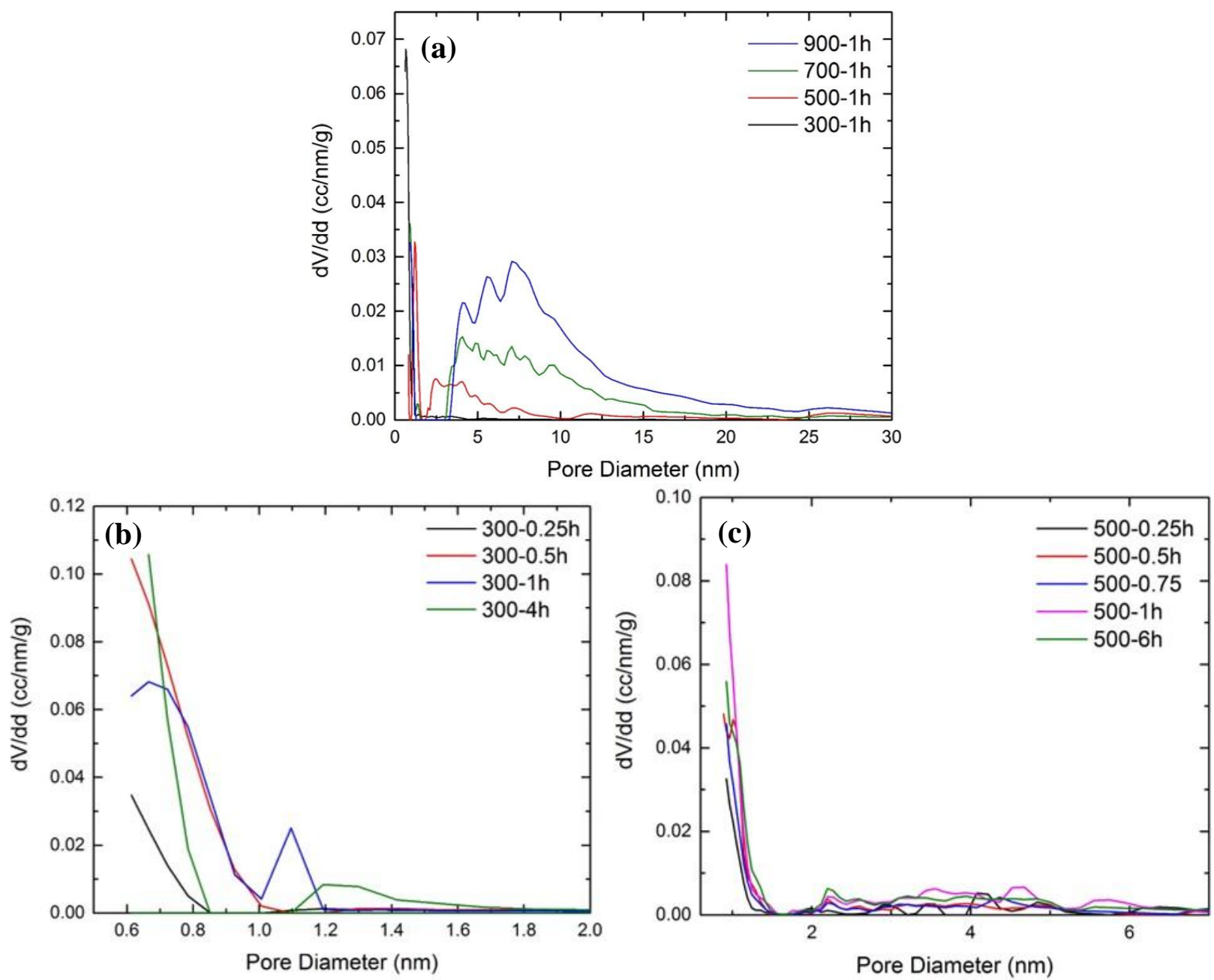

Figure 12. - Pore size distributions for (a) Different etching temperatures (b) Different etching times at $300{ }^{\circ} \mathrm{C}$ and (c) Different etching times at $500{ }^{\circ} \mathrm{C}$ for $\mathrm{Al}_{4} \mathrm{C}_{3}-\mathrm{CDCs}$

\section{7. $\mathrm{CO}_{2}$ and Water adsorption on $\mathrm{Al}_{4} \mathrm{C}_{3}-\mathrm{CDCs}$}

Water adsorption and $\mathrm{CO}_{2}$ adsorption studies were performed on the samples to probe the impact of residual aluminum species on adsorption. The water isotherm collected at $25^{\circ} \mathrm{C}$ show a range of uptake from 12.5-35.0 $\mathrm{mmol} \mathrm{g}^{-1}$ as seen in Figure 13. The samples etched at 300-500 ${ }^{\circ} \mathrm{C}$ exhibit type IV isotherms and show the majority of their uptake before a relative pressure of 0.4. This region of uptake can be attributed to the mainly microporous structure of the materials.[70] After a partial pressure of 0.4, adsorption is minimal with a slight increase near 0.95 relative pressure, which can be attributed to capillary condensation. Note that an increase in *Corresponding author. Tel: (404) 894-5254. E-mail: krista.walton@ chbe.gatech.edu (Krista Walton) 
pore volume from an etching temperature of $300-500{ }^{\circ} \mathrm{C}$ allows for a slightly larger adsorption saturation loading. $\mathrm{Al}_{4} \mathrm{C}_{3}-\mathrm{CDC}-700-1 \mathrm{~h}$ samples also show significant uptake before relative pressures of 0.4 , as well as a slight increase at higher relative pressures due to mesopores filling. The sample that significantly stands out is $\mathrm{Al}_{4} \mathrm{C}_{3}-\mathrm{CDC}-900-1 \mathrm{~h}$. This sample exhibits features of a type $\mathrm{V}$ isotherm with low adsorption at low partial pressures pointing towards weak gas solid affinity. The low uptake followed by a large increase can be explained by clusters of water adsorbing to the mesopores walls and reducing the pore wall radius until a critical point. At this point capillary condensation begins, and the adsorption loadings increase significantly, taking place in a region of relative pressures near 0.8 to 0.9 . Also note that functional groups on the surface of the carbon material will increase the initial water uptake as they allow clusters of water to form around them before micropore filling occurs.[70] $\mathrm{Al}_{4} \mathrm{C}_{3}-\mathrm{CDC}$ materials etched for 1 hour display uptakes that correspond to a mass increase range of $23-32 \%$, excluding materials etched at $900^{\circ} \mathrm{C}$, which is significantly higher than reports of an average weight increase of $15 \%$ for other CDC materials in humid air.[71] This result shows that the type and amount of residual metal in the partially etched material affects adsorption properties. As seen in Figure $13 \mathrm{~b}$ the amount of adsorbed water correlates strongly with residual metal content in the species. At low metal removal the adsorption behavior is almost identical for samples etched an hour or less, samples etched at $0.25 \mathrm{~h}$ are overlapped by samples etched at $0.5 \mathrm{~h}$ and $1 \mathrm{~h}$, even though there is an increase in surface area. As etching time increases up to 2 and $4 \mathrm{~h}$, the pore volume, calculated via QSDFT, in the sample increases significantly enough to allow a higher capacity for adsorption. Water stability of these samples is also of concern due to the $\mathrm{Al}_{4} \mathrm{C}_{3}$ hydrolysis reaction that produces methane.[72] To investigate the stability of the $\mathrm{Al}_{4} \mathrm{C}_{3}-\mathrm{CDC}$ materials PXRD and BET patterns were taken before and after water isotherms. Each sample studied *Corresponding author. Tel: (404) 894-5254. E-mail: krista.walton@ chbe.gatech.edu (Krista Walton) 
displayed no reduction in surface area, pore size distribution or degradation of crystalline structures.
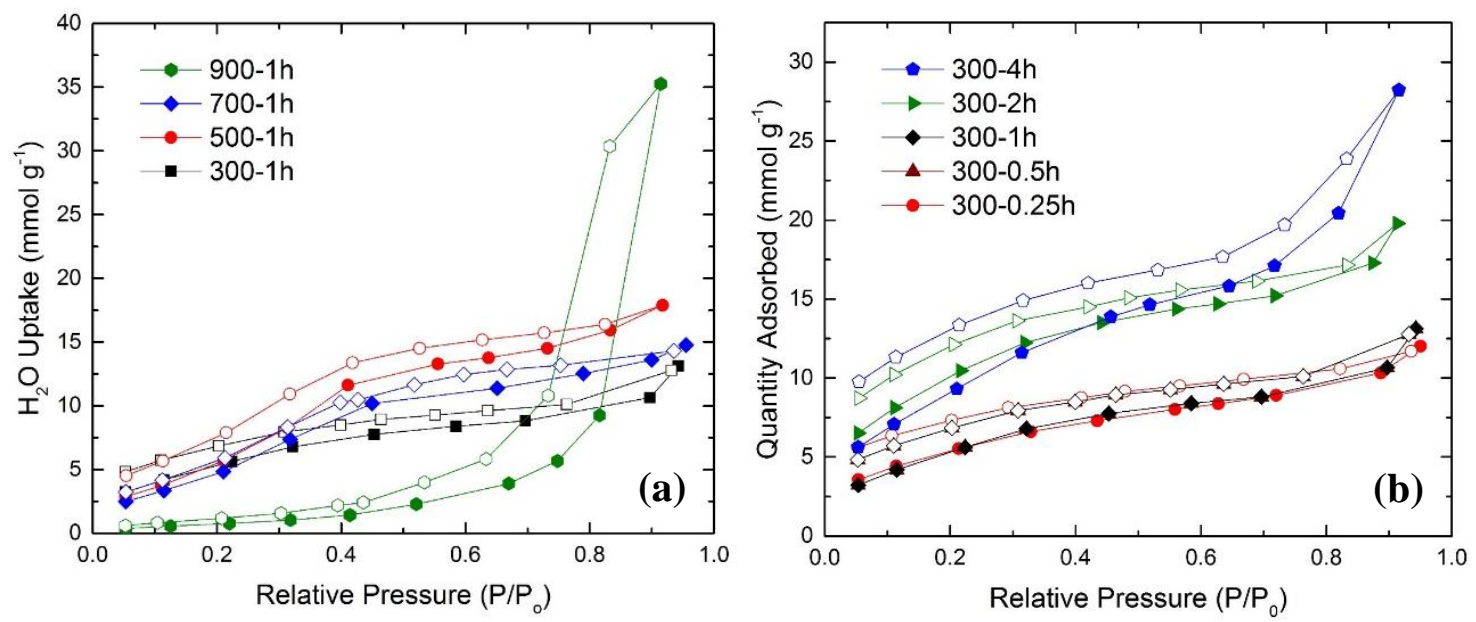

Figure 13. - Water adsorption isotherms at $25^{\circ} \mathrm{C}$ for (a) temperature trials and (b) time trials at 300 ${ }^{\circ} \mathrm{C}$.

$\mathrm{CO}_{2}$ isotherms were collected (Figure 14a) for the samples etched at different temperatures for 1 hour. $\mathrm{Al}_{4} \mathrm{C}_{3}-\mathrm{CDC}-500-1 \mathrm{~h}$ materials showed the highest $\mathrm{CO}_{2}$ capture performance from this set of samples; therefore, the $500{ }^{\circ} \mathrm{C}$ etching temperature was chosen to observe the effects that etching time will have on the materials' performance. It is important to note that none of the samples show signs of hysteresis, and sample weight before and after adsorption/desorption were the same (accuracy of $10^{-3} \mathrm{mg}$ ). This indicates that the adsorbed $\mathrm{CO}_{2}$ was completely removed from the sample after desorption, lending credence to the materials' ability to be easily regenerated. The $\mathrm{Al}_{4} \mathrm{C}_{3}-\mathrm{CDC}$ samples show no deviation in uptake for 4 consecutive cycles, demonstrating stability and promising capability for repeated use. As seen in Figure $14 \mathrm{a}$ the samples etched at 700 and $900^{\circ} \mathrm{C}$ for $1 \mathrm{~h}$ show a small initial uptake in the low pressure regions, likely due to their dominantly mesoporous structure. This same type of low relative pressure uptake is seen in ordered mesoporous carbon.[73] At higher pressure regions

*Corresponding author. Tel: (404) 894-5254. E-mail: krista.walton@ chbe.gatech.edu (Krista Walton) 
these samples show a linear increase in capacity due to mesopores being partially filled and the entire pore volume of the sample not being utilized at the recorded pressures. The $\mathrm{Al}_{4} \mathrm{C}_{3}-\mathrm{CDC}$ 300-1h samples show a high initial uptake into the micropores for pressures less than 1 bar, then drop off significantly, consistent with low pore volume at higher pressures. By increasing the etching temperature, $\mathrm{Al}_{4} \mathrm{C}_{3}-\mathrm{CDC}-500-1 \mathrm{~h}$ samples show an increased capacity for $\mathrm{CO}_{2}$ uptake for the entire 20 bar pressure range with 2.74 mmol g ${ }^{-1}$ at 1 bar. $\mathrm{CO}_{2}$ adsorption in $\mathrm{Al}_{4} \mathrm{C}_{3}-\mathrm{CDC}-500$ 1h shows improved adsorption compared to BPL activated carbon, which possesses similar carbon properties but no residual metal species. BPL has a reported BET surface area in the range of $1000-1100 \mathrm{~m}^{2} \mathrm{~g}^{-1}$ and a pore volume range of $0.49-0.7 \mathrm{cc} \mathrm{g}^{-1}$ with a demonstrated adsorption of $\mathrm{CO}_{2}$ around $2.1 \mathrm{mmol} \mathrm{g}^{-1}$ at 1 bar and $25^{\circ} \mathrm{C}$.[74-77] Other highly activated carbon materials have shown the upper end of $\mathrm{CO}_{2}$ adsorption loadings in carbon to be $2.9-4.7 \mathrm{mmol} \mathrm{g}^{-1}$. This corresponds to $1 \mathrm{mmol}$ of $\mathrm{CO}_{2}$ adsorbed per $565-1050 \mathrm{~m}^{2}$ of carbonaceous surface at 1 bar and $25^{\circ} \mathrm{C}$.[78] $\mathrm{Al}_{4} \mathrm{C}_{3}-\mathrm{CDC}-500-1$, which receives no post-synthetic processing, demonstrates a slightly smaller adsorption compared to these highly activated materials per gram, but displays an adsorption of $1 \mathrm{mmol}$ of $\mathrm{CO}_{2}$ for every $410 \mathrm{~m}^{2}$ of CDC surface, which demonstrates a higher capacity per available surface area than other highly tuned materials. This demonstrates that the interactive surface of some $\mathrm{Al}_{4} \mathrm{C}_{3}-\mathrm{CDC}$ materials are more efficient at interacting with acid gases, such as $\mathrm{CO}_{2}$, than other highly modified carbon sorbents. The combination of micro and mesopores in $\mathrm{Al}_{4} \mathrm{C}_{3}$ - $\mathrm{CDC}-500-1 \mathrm{~h}$ allows for a high initial uptake that does not level off after micropore filling. The larger surface area leads to continuously increasing adsorption at moderate pressures after 1 bar as it continues to have its mesopores filled at higher pressures. Note that due to the samples having a variety of physical properties derived from their respective etching temperature, no straightforward correlation can be made with only residual aluminum,

*Corresponding author. Tel: (404) 894-5254. E-mail: krista.walton@ chbe.gatech.edu (Krista Walton) 
surface area or pore volume. The samples etched at $500^{\circ} \mathrm{C}$ at various times do show results that are directly correlated with surface area and pore volume. Since the pore size distribution does not deviate drastically at various etching times, the initial uptake in the micropores is almost identical for all time samples except those etched for $0.25 \mathrm{~h}$. The reduced adsorption in samples etched for $0.25 \mathrm{~h}$ is most likely due to high residual metal content in the sample, in which PXRD shows evidence of unreacted carbide, leading to $\mathrm{Al}_{4} \mathrm{C}_{3}-\mathrm{CDC}-500-0.25 \mathrm{~h}$ having the lowest pore volume and capacity. At different etching times, both the pore volume and surface area of the samples show a linear relationship with the materials' $\mathrm{CO}_{2}$ uptake at 1 bar and $25^{\circ} \mathrm{C}$.
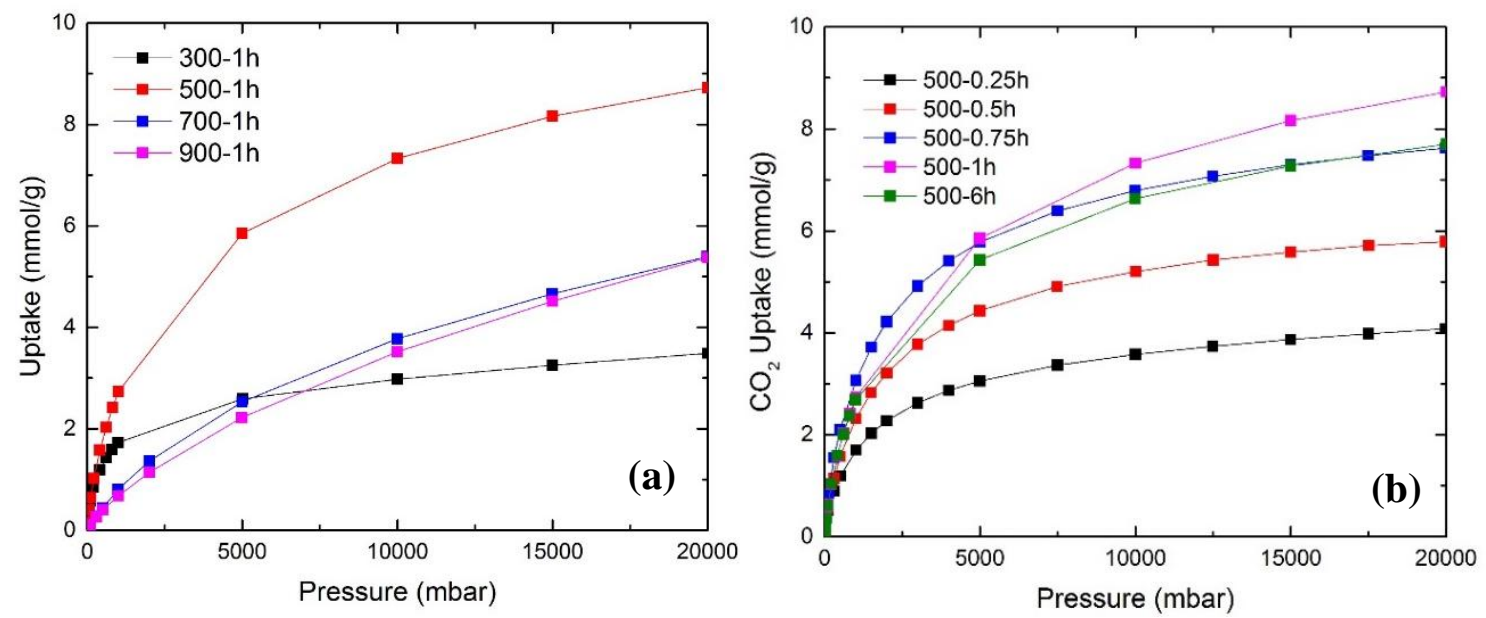

Figure 14. $-\mathrm{CO}_{2}$ adsorption isotherms at $25{ }^{\circ} \mathrm{C}$ for $\mathrm{Al}_{4} \mathrm{C}_{3}-\mathrm{CDC}$ samples etched at (a) different temperatures $300-900{ }^{\circ} \mathrm{C}$, for 1 hour and (b) at $500^{\circ} \mathrm{C}$ for various times $(0.25-6$ hours $)$.

\section{Conclusions}

After reaction of the aluminum heteroatoms from $\mathrm{Al}_{4} \mathrm{C}_{3}$ via chlorination at different temperatures and times, the physical properties of the materials were examined. The residual aluminum content of the $\mathrm{Al}_{4} \mathrm{C}_{3}$-CDC material decreases in a repeatable trend as both time and temperature increase. By varying etching temperature from $300-900^{\circ} \mathrm{C}$, a range of surface areas were generated with the maximum being $\left(1126 \mathrm{~m}^{2} \mathrm{~g}^{-1}\right)$ when the carbide was etched at $500^{\circ} \mathrm{C}$ for *Corresponding author. Tel: (404) 894-5254. E-mail: krista.walton@ chbe.gatech.edu (Krista Walton) 
1h. Etching temperature enables the pore size distribution to be tuned from a material entirely microporous in $\mathrm{Al}_{4} \mathrm{C}_{3}-\mathrm{CDC}-300-1 \mathrm{~h}$, to mainly mesoporous samples at higher etching temperatures. This demonstrates the ability of $\mathrm{Al}_{4} \mathrm{C}_{3}-\mathrm{CDCs}$ to be versatile in terms of tunable pore size for a desired application. Also seen during partial etching were aluminum based nanoparticles as well as aluminum based clusters on the surface of certain $\mathrm{Al}_{4} \mathrm{C}_{3}$-CDC samples. These particles have been observed to be present in larger quantities at lower etching temperatures with few observed at elevated temperatures up to $900^{\circ} \mathrm{C}$. The crystalline form of the residual metal is observed to change at an elevated etching temperature of $700^{\circ} \mathrm{C}$, from aluminum based nanoparticles to crystalline $\alpha-\mathrm{Al}_{2} \mathrm{O}_{3}$. EDS, PXRD, XPS and NMR results indicated that the form of the aluminum at etching temperatures of 300 and $500^{\circ} \mathrm{C}$ have a strong potential to be an amorphous composition of $\mathrm{Al}_{2} \mathrm{O}_{3}, \mathrm{AlCl}_{3}, \mathrm{Al}(\mathrm{OH})_{3}$ and $\mathrm{BAC}$. Carbon structures were also observed in the samples with an increasing presence at higher temperatures, these structures varied from carbonaceous microspheres to graphene sheets. Adsorption properties were also investigated with respect to water and $\mathrm{CO}_{2}$. Water adsorption shows a dependence on residual metal content as well as the presence of carbon structures. BET surface area and PXRD patterns after exposure have shown that the samples are stable in water vapor with no recorded loss of surface area, pore size distribution and crystal structure. $\mathrm{CO}_{2}$ adsorption demonstrates a strong dependence on etching temperature and time. Holding etching time at $1 \mathrm{~h}$ and increasing the temperature drastically effects the $\mathrm{CO}_{2}$ adsorption properties. This can be attributed to changes in surface area, pore size, carbon structures, and residual aluminum content. Materials etched at 300 and $500^{\circ} \mathrm{C}$ show high adsorption capacity at low pressures with adsorption at 1 bar and $25^{\circ} \mathrm{C}$ reaching as high as $2.74 \mathrm{mmol} \mathrm{g}^{-1}$ for $\mathrm{Al}_{4} \mathrm{C}_{3}-500-1 \mathrm{~h}$, which is superior to BPL adsorption capacity, an activated carbon with comparable properties, and shows a more efficient

*Corresponding author. Tel: (404) 894-5254. E-mail: krista.walton@ chbe.gatech.edu (Krista Walton) 
use of surface area than highly activated carbon materials. Materials etching at 700 and $900^{\circ} \mathrm{C}$ show a linear increase in $\mathrm{CO}_{2}$ adsorption throughout the pressures investigated with their pore volumes not seeing a saturation point up to 20 bar. This investigation has demonstrated that an effective one pot synthesis can be used on the $\mathrm{Al}_{4} \mathrm{C}_{3}$ precursor to generate a porous-carbon material with aluminum based nanoparticles that show promise for adsorption based applications.

*Corresponding author. Tel: (404) 894-5254. E-mail: krista.walton@ chbe.gatech.edu (Krista Walton) 


\section{Acknowledgements}

This work is supported by the Center for Understanding and Control of Acid Gas-Induced Evolution of Materials for Energy (UNCAGE-ME), an Energy Frontier Research Center funded by U.S. Department of Energy (US DoE), Office of Science, Basic Energy Sciences (BES) under Award no. DE-SC0012577.

*Corresponding author. Tel: (404) 894-5254. E-mail: krista.walton@ chbe.gatech.edu (Krista Walton) 


\section{References}

[1] Saha D, Bao Z, Jia F, Deng S. Adsorption of CO2, CH4, N2O, and N2 on MOF-5, MOF-177, and Zeolite 5A. Environmental Science \& Technology. 2010;44(5):1820-6.

[2] Newcombe G, Drikas M, Hayes R. Influence of characterised natural organic material on activated carbon adsorption: II. Effect on pore volume distribution and adsorption of 2methylisoborneol. Water Research. 1997;31(5):1065-73.

[3] Eisenbach D, Gallei E. Infrared spectroscopic investigations relating to coke formation on zeolites. Journal of Catalysis. 1979;56(3):377-89.

[4] Sevilla M, Fuertes AB. Sustainable porous carbons with a superior performance for $\mathrm{CO} 2$ capture. Energy \& Environmental Science. 2011;4(5):1765-71.

[5] Kyotani T. Control of pore structure in carbon. Carbon. 2000;38(2):269-86.

[6] Becker P, Glenk F, Kormann M, Popovska N, Etzold BJM. Chlorination of titanium carbide for the processing of nanoporous carbon: A kinetic study. Chemical Engineering Journal. 2010;159(1-3):236-41.

[7] Gogotsi YG, Kofstad P, Yoshimura M, Nickel KG. Formation of sp3-bonded carbon upon hydrothermal treatment of SiC. Diamond and Related Materials. 1996;5(2):151-62.

[8] Yushin G, Hoffman EN, Barsoum MW, Gogotsi Y, Howell CA, Sandeman SR, et al. Mesoporous carbide-derived carbon with porosity tuned for efficient adsorption of cytokines. Biomaterials. 2006;27(34):5755-62.

[9] Osswald S, Portet C, Gogotsi Y, Laudisio G, Singer JP, Fischer JE, et al. Porosity control in nanoporous carbide-derived carbon by oxidation in air and carbon dioxide. Journal of Solid State Chemistry. 2009;182(7):1733-41.

[10] Simon P, Gogotsi Y. Materials for electrochemical capacitors. Nat Mater. 2008;7(11):845-54.

[11] Laheäär A, Jänes A, Lust E. Electrochemical properties of carbide-derived carbon electrodes in non-aqueous electrolytes based on different Li-salts. Electrochimica Acta. 2011;56(25):9048-55.

[12] Gogotsi Y, Nikitin A, Haihui Y, Wei Z, Fischer JE, Bo Y, et al. Nanoporous carbide-derived carbon with tunable pore size. Nature Materials. 2003;2(9):591-4.

[13] Presser V, Heon M, Gogotsi Y. Carbide-Derived Carbons - From Porous Networks to Nanotubes and Graphene. Advanced Functional Materials. 2011;21(5):810-33.

[14] Mangarella MC, Ewbank JL, Dutzer MR, Alamgir FM, Walton KS. Synthesis of embedded iron nanoparticles in Fe3C-derived carbons. Carbon. 2014;79:74-84.

[15] Mangarella MC, Walton KS. Tailored Fe3C-derived carbons with embedded Fe nanoparticles for ammonia adsorption. Carbon. 2015;95:208-19.

[16] Borchardt L, Hasché F, Lohe MR, Oschatz M, Schmidt F, Kockrick E, et al. Transition metal loaded silicon carbide-derived carbons with enhanced catalytic properties. Carbon. 2012;50(5):1861-70.

[17] Petit C, Karwacki C, Peterson G, Bandosz TJ. Interactions of Ammonia with the Surface of Microporous Carbon Impregnated with Transition Metal Chlorides. The Journal of Physical Chemistry C. 2007;111(34):12705-14.

[18] Molina-Sabio M, Pérez V, Rodríguez-Reinoso F. Impregnation of activated carbon with chromium and copper salts: Effect of porosity and metal content. Carbon. 1994;32(7):1259-65.

[19] Li H, Zhu L, Wang J, Li L, Shih K. Development of Nano-Sulfide Sorbent for Efficient Removal of Elemental Mercury from Coal Combustion Fuel Gas. Environmental Science \& Technology. 2016;50(17):9551-7.

[20] Liu W, Vidic RD, Brown TD. Impact of Flue Gas Conditions on Mercury Uptake by SulfurImpregnated Activated Carbon. Environmental Science \& Technology. 2000;34(1):154-9.

[21] Henning KD, Schäfer S. Impregnated activated carbon for environmental protection. Gas Separation \& Purification. 1993;7(4):235-40.

*Corresponding author. Tel: (404) 894-5254. E-mail: krista.walton@ chbe.gatech.edu (Krista Walton) 
[22] Liu W, Vidić RD, Brown TD. Optimization of Sulfur Impregnation Protocol for Fixed-Bed Application of Activated Carbon-Based Sorbents for Gas-Phase Mercury Removal. Environmental Science \& Technology. 1998;32(4):531-8.

[23] Bhatnagar A, Hogland W, Marques M, Sillanpää M. An overview of the modification methods of activated carbon for its water treatment applications. Chemical Engineering Journal. 2013;219:499-511.

[24] Jiang SP. A review of wet impregnation-An alternative method for the fabrication of high performance and nano-structured electrodes of solid oxide fuel cells. Materials Science and Engineering: A. 2006;418(1-2):199-210.

[25] Atkinson JD, Fortunato ME, Dastgheib SA, Rostam-Abadi M, Rood MJ, Suslick KS. Synthesis and characterization of iron-impregnated porous carbon spheres prepared by ultrasonic spray pyrolysis. Carbon. 2011;49(2):587-98.

[26] Aarset K, Shen Q, Thomassen H, Richardson AD, Hedberg K. Molecular Structure of the Aluminum Halides, Al2Cl6, AlCl3, Al2Br6, AlBr3, and All3, Obtained by Gas-Phase Electron-Diffraction and ab Initio Molecular Orbital Calculations. The Journal of Physical Chemistry A. 1999;103(11):1644-52. [27] Hartman M, Trnka O, Šolcová O. Thermal Decomposition of Aluminum Chloride Hexahydrate. Industrial \& Engineering Chemistry Research. 2005;44(17):6591-8.

[28] Yang Z, Gao B, Wang Y, Wang Q, Yue Q. Aluminum fractions in surface water from reservoirs by coagulation treatment with polyaluminum chloride (PAC): Influence of initial $\mathrm{pH}$ and $\mathrm{OH}-/ \mathrm{Al} 3+$ ratio. Chemical Engineering Journal. 2011;170(1):107-13.

[29] Bergman LH. Oxidation method for production of special aluminas from pure aluminum chloride. Google Patents 1987.

[30] Park HK, Park KY, Jung KY. Alumina-Precursor Nanoparticles Prepared by Partial Hydrolysis of $\mathrm{AlCl} 3$ Vapor in Tubular Flow Reactor: Effect of Hydrolysis Conditions on Particle Size Distribution. Industrial \& Engineering Chemistry Research. 2014;53(25):10372-9.

[31] Park KY, Park Y-W, Youn S-H, Choi S-Y. Bench-Scale Decomposition of Aluminum Chloride Hexahydrate to Produce Poly(aluminum chloride). Industrial \& Engineering Chemistry Research. 2000;39(11):4173-7.

[32] Park HK, Park KY, Kim H-J. Kinetics of Gas-Phase Hydrolysis of Aluminum Chloride for Alumina Particles. Industrial \& Engineering Chemistry Research. 2014;53(39):14956-62.

[33] Khaleel A, Kapoor PN, Klabunde KJ. Nanocrystalline metal oxides as new adsorbents for air purification. Nanostructured Materials. 1999;11(4):459-68.

[34] Carnes CL, Kapoor PN, Klabunde KJ, Bonevich J. Synthesis, Characterization, and Adsorption Studies of Nanocrystalline Aluminum Oxide and a Bimetallic Nanocrystalline Aluminum Oxide/Magnesium Oxide. Chemistry of Materials. 2002;14(7):2922-9.

[35] Tanada S, Kabayama M, Kawasaki N, Sakiyama T, Nakamura T, Araki M, et al. Removal of phosphate by aluminum oxide hydroxide. Journal of Colloid and Interface Science. 2003;257(1):135-40.

[36] Goodman AL, Li P, Usher CR, Grassian VH. Heterogeneous Uptake of Sulfur Dioxide On Aluminum and Magnesium Oxide Particles. The Journal of Physical Chemistry A. 2001;105(25):6109-20.

[37] Baltrusaitis J, Schuttlefield J, Zeitler E, Grassian VH. Carbon dioxide adsorption on oxide nanoparticle surfaces. Chemical Engineering Journal. 2011;170(2-3):471-81.

[38] Perkson A, Leis J, Arulepp M, Kaarik M, Urbonaite S, Svensson G. Barrel-like carbon nanoparticles from carbide by catalyst assisted chlorination. Carbon. 2003;41(9):1729-35.

[39] Leis J, Perkson A, Arulepp M, Käärik M, Svensson G. Carbon nanostructures produced by chlorinating aluminium carbide. Carbon. 2001;39(13):2043-8.

[40] Bartolucci SF, Paras J, Rafiee MA, Rafiee J, Lee S, Kapoor D, et al. Graphene-aluminum nanocomposites. Materials Science and Engineering: A. 2011;528(27):7933-7.

*Corresponding author. Tel: (404) 894-5254. E-mail: krista.walton@ chbe.gatech.edu (Krista Walton) 
[41] Lätt M, Käärik M, Permann L, Kuura H, Arulepp M, Leis J. A structural influence on the electrical double-layer characteristics of Al4C3-derived carbon. Journal of Solid State Electrochemistry. 2010;14(4):543-8.

[42] Jacob M, Palmqvist U, Alberius PCA, Ekstrom T, Nygren M, Lidin S. Synthesis of structurally controlled nanocarbons-in particular the nanobarrel carbon. Solid State Sciences. 2003;5(1):133-7.

[43] Jänes A, Lust E. Electrochemical Characteristics of Nanoporous Carbide-Derived Carbon Materials in Various Nonaqueous Electrolyte Solutions. Journal of The Electrochemical Society. 2006;153(1):A113-A6.

[44] Smith DF, Essex H. Process of making aluminum chlorid. Google Patents 1918.

[45] Klemperer W. Infrared Spectrum of Gaseous Aluminum Chloride. The Journal of Chemical Physics. 1956;24(2):353-5.

[46] Thomberg T, Kurig H, Jänes A, Lust E. Mesoporous carbide-derived carbons prepared from different chromium carbides. Microporous \& Mesoporous Materials. 2011;141(1-3):88-93.

[47] Chen X, Cantrell DR, Kohlhaas K, Stankovich S, Ibers JA, Jaroniec M, et al. Carbide-Derived Nanoporous Carbon and Novel Core-Shell Nanowires. Chemistry of Materials. 2006;18(3):753-8.

[48] Bräuniger T, Chandran CV, Wedig U, Jansen M. NMR Chemical Shift and Quadrupolar Interaction Parameters of Carbon - Coordinated 27Al in Aluminium Carbide, Al4C3. Zeitschrift für anorganische und allgemeine Chemie. 2011;637(5):530-5.

[49] Czjzek G, Fink J, Götz F, Schmidt H, Coey JMD, Rebouillat JP, et al. Atomic coordination and the distribution of electric field gradients in amorphous solids. Physical Review B. 1981;23(6):2513-30.

[50] Massiot D, Fayon F, Capron M, King I, Le Calvé S, Alonso B, et al. Modelling one - and two - dimensional solid - state NMR spectra. Magnetic Resonance in Chemistry. 2002;40(1):70-6.

[51] Sarou-Kanian V, Gleizes AN, Florian P, Samélor D, Massiot D, Vahlas C. Temperature-Dependent 4-, 5- and 6-Fold Coordination of Aluminum in MOCVD-Grown Amorphous Alumina Films: A Very High Field 27Al-NMR study. The Journal of Physical Chemistry C. 2013;117(42):21965-71.

[52] Cerny Z, Machacek J, Fusek J, Casensky B, Kriz O, G. Tuck D. Aluminium-27 and 71Ga NMR studies of the solution chemistry of $\mathrm{Ga}[\mathrm{AICl} 4]$ and related compounds. Journal of the Chemical Society, Dalton Transactions. 1998(9):1439-46.

[53] Jakobsen HJ, Skibsted J, Bildsøe H, Nielsen NC. Magic-angle spinning NMR spectra of satellite transitions for quadrupolar nuclei in solids. Journal of Magnetic Resonance (1969). 1989;85(1):173-80.

[54] O'Dell LA, Savin SLP, Chadwick AV, Smith ME. A 27AI MAS NMR study of a sol-gel produced alumina: Identification of the NMR parameters of the $\theta-A 1203$ transition alumina phase. Solid State Nuclear Magnetic Resonance. 2007;31(4):169-73.

[55] Hauert R, Patscheider J, Tobler M, Zehringer R. XPS investigation of the aC: H/Al interface. Surface science. 1993;292(1-2):121-9.

[56] Natishan PM, O'grady WE. Chloride ion interactions with oxide-covered aluminum leading to pitting corrosion: a review. Journal of The Electrochemical Society. 2014;161(9):C421-C32.

[57] Augustynski J, Painot J. Discussion of "On the Kinetics of the Breakdown of Passivity of Preanodized Aluminum by Chloride Ions" [Z. A. Foroulis and M. I. Thubrikar (pp. 1296-1301, Vol. 122, No. 10)]. Journal of The Electrochemical Society. 1976;123(6):841.

[58] Rotole JA, Sherwood PMA. Valence band x-ray photoelectron spectroscopic studies to distinguish between oxidized aluminum species. Journal of Vacuum Science \& Technology A. 1999;17(4):1091-6.

[59] McCafferty E. Sequence of steps in the pitting of aluminum by chloride ions. Corrosion Science. 2003;45(7):1421-38.

[60] Pérez-Cadenas A, amp, x, n F, Maldonado-Hódar FJ, Moreno-Castilla C. On the nature of surface acid sites of chlorinated activated carbons. Carbon. 2003;41(3):473-8.

*Corresponding author. Tel: (404) 894-5254. E-mail: krista.walton@ chbe.gatech.edu (Krista Walton) 
[61] Papirer E, Lacroix R, Donnet J-B, Nansé G, Fioux P. XPS study of the halogenation of carbon black-Part 2. Chlorination. Carbon. 1995;33(1):63-72.

[62] Zhou J-H, Sui Z-J, Zhu J, Li P, Chen D, Dai Y-C, et al. Characterization of surface oxygen complexes on carbon nanofibers by TPD, XPS and FT-IR. Carbon. 2007;45(4):785-96.

[63] Pang H, Wang X, Zhang G, Chen H, Lv G, Yang S. Characterization of diamond-like carbon films by SEM, XRD and Raman spectroscopy. Applied Surface Science. 2010;256(21):6403-7.

[64] Feng Z-S, Chen J-J, Zhang R, Zhao N. Formation of Al2O3-Nb2O5 composite oxide films on lowvoltage etched aluminum foil by complexation-precipitation and anodizing. Ceramics International. 2012;38(4):3057-61.

[65] Santos PS, Santos HS, Toledo S. Standard transition aluminas. Electron microscopy studies. Materials Research. 2000;3(4):104-14.

[66] Heyman A, Musgrave CB. A Quantum Chemical Study of the Atomic Layer Deposition of Al2O3 Using AlCl3 and $\mathrm{H} 2 \mathrm{O}$ as Precursors. The Journal of Physical Chemistry B. 2004;108(18):5718-25.

[67] Matero R, Rahtu A, Ritala M, Leskelä M, Sajavaara T. Effect of water dose on the atomic layer deposition rate of oxide thin films. Thin Solid Films. 2000;368(1):1-7.

[68] Balbuena PB, Gubbins KE. Theoretical interpretation of adsorption behavior of simple fluids in slit pores. Langmuir. 1993;9(7):1801-14.

[69] Solozhenko VL, Kurakevych OO. Equation of state of aluminum carbide Al4C3. Solid State Communications. 2005;133(6):385-8.

[70] Do DD, Do HD. A model for water adsorption in activated carbon. Carbon. 2000;38(5):767-73.

[71] Kippeny TC. Chemically modified organic cdc based rapid analysis system. Google Patents 2011.

[72] Schneider RT, Hauck FA. Method for methane production. Google Patents 1990.

[73] Yuan B, Wu X, Chen Y, Huang J, Luo H, Deng S. Adsorption of CO2, CH4, and N2 on Ordered Mesoporous Carbon: Approach for Greenhouse Gases Capture and Biogas Upgrading. Environmental Science \& Technology. 2013;47(10):5474-80.

[74] Kikkinides ES, Yang RT, Cho SH. Concentration and recovery of carbon dioxide from flue gas by pressure swing adsorption. Industrial \& Engineering Chemistry Research. 1993;32(11):2714-20.

[75] Sircar S, Golden T, Rao M. Activated carbon for gas separation and storage. Carbon. 1996;34(1):1-12.

[76] Russell BP, Levan MD. Pore size distribution of BPL activated carbon determined by different methods. Carbon. 1994;32(5):845-55.

[77] McEwen J, Hayman J-D, Ozgur Yazaydin A. A comparative study of CO2, CH4 and N2 adsorption in ZIF-8, Zeolite-13X and BPL activated carbon. Chemical Physics. 2013;412:72-6.

[78] Wahby A, Ramos-Fernández JM, Martínez-Escandell M, Sepúlveda-Escribano A, Silvestre-Albero $\mathrm{J}$, Rodríguez-Reinoso F. High-surface-area carbon molecular sieves for selective $\mathrm{CO} 2$ adsorption. ChemSusChem. 2010;3.

*Corresponding author. Tel: (404) 894-5254. E-mail: krista.walton@ chbe.gatech.edu (Krista Walton) 


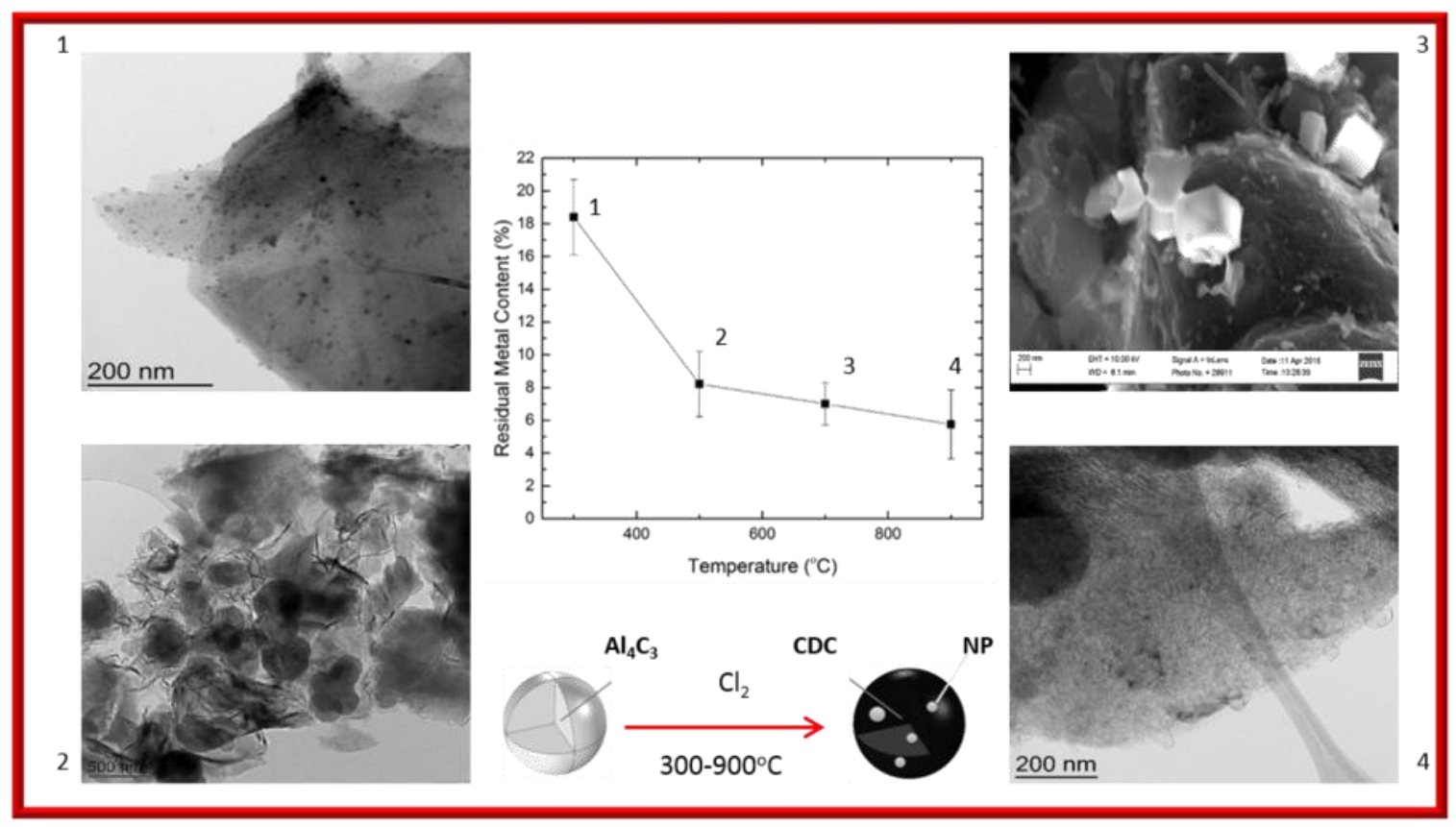

*Corresponding author. Tel: (404) 894-5254. E-mail: krista.walton@ chbe.gatech.edu (Krista Walton) 